Research Article

\title{
Decision Optimization of Four-Level Supply Chain with the Participation of Two-Echelon Logistics Service Providers under Different Power Structures
}

\author{
Jianjun Zhang ${ }^{1}{ }^{1}$ and Zhigang Song $\mathbb{D}^{2}$ \\ ${ }^{1}$ School of Economics and Management, Inner Mongolia Agricultural University, Hohhot 010010, China \\ ${ }^{2}$ School of Management and Engineering, Zhengzhou University of Aeronautics, Zhengzhou 450046, China \\ Correspondence should be addressed to Zhigang Song; songzhigang1980@126.com
}

Received 3 February 2021; Revised 22 March 2021; Accepted 3 April 2021; Published 22 April 2021

Academic Editor: Josefa Mula

Copyright (c) 2021 Jianjun Zhang and Zhigang Song. This is an open access article distributed under the Creative Commons Attribution License, which permits unrestricted use, distribution, and reproduction in any medium, provided the original work is properly cited.

\begin{abstract}
Taking the four-level supply chain participated by two-echelon logistics service providers as the research object, this paper deeply studies the influence of different power structures on the optimal price and logistics service level decisions of the whole supply chain system. On this basis, this paper points out the optimal power structure of the whole supply chain system and then discusses the optimal cooperative decision-making mode to improve the operation efficiency of the supply chain system under optimal power structure. The results show that compared with the two power structures of manufacturer-led and logistics service integrator-led, the retailer-led structure is the optimal power structure, whether from the perspective of maximizing the total profit of the supply chain or the surplus of consumers. When the supply chain is facing consumers who are less sensitive to the retail price of products and more sensitive to the logistics service level, the advantages of retail-led decentralized supply chain are more significant. The centralized decision of product supply chain (PSC) and logistics service supply chain (LSSC) under different power structures is the dominant strategy, and the equilibrium strategy is Nash game adopted by both parties. At this time, the total profit of the supply chain system is the largest and the total social welfare is the largest, while the total profit and consumer surplus of the supply chain under LSSC-led structure are the smallest. When the supply chain is facing consumers with low sensitivity of logistics service level and product retail price, PSC and LSSC have more significant advantages in Nash game rather than Stackelberg game.
\end{abstract}

\section{Introduction}

Logistics is the source of the germination of supply chain ideas and the pillar of the in-depth development of supply chain practices [1]. Therefore, logistics service providers play an important role in the research of supply chain management and decision-making. That is to say, in the operation management and decision-making of supply chain, the logistics service and the entities that provided logistics service are included in the supply chain to have an overall consideration in order to achieve a more realistic research conclusion. However, most of the current academic research on supply chain decision-making and coordination lacks consideration and attention to logistics service providers. The specialized division of labor and rapid development of logistics make the application of logistics service supply chain (LSSC) emerge, which can provide integrated logistics solutions based on the complexity of product supply chain (PSC) logistics services; that is, due to the diversity and complexity of the demand for logistics services in the product supply chain, the logistics services provided by a single logistics company obviously cannot better meet customers' needs [2]. At this time, it is necessary for the logistics service integrator (LSI) to integrate the functional logistics service provider (FLSP) to meet the customers' customized logistics service needs, thus forming a supply chain system with the participation of twoechelon logistics service providers, as shown in Figure 1.

The supply chain system participated by the two-echelon logistics service providers includes both the PSC composed 


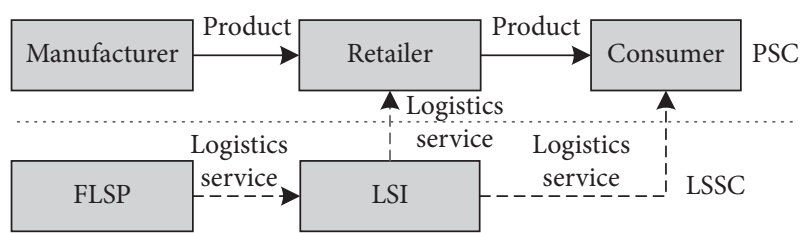

FIGURE 1: Supply chain system involving two-echelon logistics service providers.

of manufacturer and retailer, and the LSSC composed of LSI and FLSP. The goal of LSSC is to provide integrated logistics services for PSC by integrating various scattered logistics organizations [3]. As a PSC subchain, LSSC must be fully integrated into PSC, only by doing so can it better improve the logistics service level (including lead time [4], rapid response capacity, and logistics service types and quality) and overall competitiveness of the entire supply chain system and maximize the economic benefits of the entire supply chain system. Therefore, it is necessary to take the entire supply chain system composed of PSC and LSSC as the research object, while this paper focuses on the optimal decisions of the supply chain system participated by the twoechelon logistics service providers under different power structures (a system composed of two-echelon product supply chain and two-echelon logistics service supply chain).

For example, JD logistics uses logistics network and logistics cloud, logistics technology, logistics data, and other resources to provide transportation, storage, packaging, distribution, customer service, information, and comprehensive solution of after-sales integration of forward and reverse supply chain for the retailer's supply chain. The construction of its supply chain logistics system has united many partners, for example, it established a joint venture company with COSCO to build a comprehensive international supply chain service platform. And it signed cooperation agreements with Huamao International Logistics Co. Ltd., Jiangsu Xinning Modern Logistics Co. Ltd., and Beijing Huahong Co. Ltd. in order to carry out all-round cooperation on intelligent logistics and logistics platform ecology, which can provide retailers and their downstream customers with high-quality supply chain integrated logistics services. For another example, as a professional logistics service integrator, Xiamen Hongxin International Logistics Co. Ltd. has built a relatively complete regional logistics service network through the integration of logistics resources, which can provide storage, transportation, distribution, and dispatching service for the customer's product supply chain [5]. Thus, it forms a supply chain system participated by the twoechelon logistics service providers.

Since there are many companies involved in the supply chain system with the participation of two-echelon logistics service providers, different cooperative decision-making modes exist among companies, including decentralized decision-making mode and partial cooperative decision-making mode. For example, there exist many decision-making situations such as manufacturer-retailer cooperative decisionmaking mode, LSI-FLSP cooperative decision-making mode, and the decentralized decision-making mode. The difference of cooperative decision-making modes plays an essential role on the operational efficiency of the entire supply chain. At the same time, since each enterprise is an independent decision maker and has their own "power," they are willing to obtain more profits through their dominant power. EI-Ansary and Stern [6] define this power as "a member controls the decisions of other members in market competition." At present, in the entire supply chain system, there is a power structure dominated by manufacturing companies (such as Lenovo, Xiaomi, and Haier) earlier, and there exist situations where the dominant position of manufacturing companies is balanced and surpassed by large retail companies, that is, the power structure dominated by retail giants (such as Gome and Wal-Mart). And there is also a situation in which large LSIs have gradually changed from an auxiliary role in the past to a new leading force in the supply chain. That is to say, the power structure is dominated by logistics service integrators such as JD Logistics, Cainiao Logistics, UPS, and other emerging market entities. Their logistics service level and operational capabilities affect the decision behavior of upstream and downstream members of the supply chain [7].

Therefore, based on the above observations, this paper will mainly discuss the following questions:

(1) Changes in the power structure of the supply chain have an important impact on the profitability, market competitiveness and social welfare of decision makers, and the entire supply chain system [8-10]. Which type of power structure can better improve the profit level of the entire supply chain system?

(2) Which cooperative decision-making mode is conducive to improving the operational efficiency and competitive advantage of the entire supply chain system?

(3) To what extent does consumers' sensitivity coefficient of retail price and logistics service level influence the optimal power structure and the optimal cooperative decision-making mode?

Addressing the above important research questions highlights the research objectives and contributions of this paper. To the best of our knowledge, this is the first paper which will focus on multiple power structures and deeply study the optimal decisions of the supply chain involving two-echelon logistics service providers under different cooperative decision-making modes. Our approach, in this paper, is essentially different from those presented in previous models in which the channel is controlled only by the manufacturer or the retailer, such as Nikunja et al. [11] and $\mathrm{Yu}$ and Xiao [12]. This paper will study multiple power structures, analyze the influence of power structures on the optimal decisions of each participant in the supply chain, the total profit of the supply chain, and consumer welfare, and clarify the optimal power structure of the entire supply chain system. In the meantime, different from Li et al. [13] and Giri et al. [14], this paper will further discuss the optimal cooperative decision-making mode under the optimal power 
structure to improve the operation efficiency of the supply chain system with the participation of two-echelon logistics service providers.

The remainder of the paper is organized as follows. In the following section, this paper will briefly review the relevant literature and introduce the conceptual model of the fourlevel supply chain participated by the two-echelon logistics service providers in Section 3. Section 4 analyzes the optimal decisions of each decision maker under different power structures. Section 5 analyzes the impact of the difference in power structures on the optimal decisions of the supply chain, and numerical examples are provided in Section 6 to illustrate the results. The conclusions and some possible directions of future research are arranged in Section 7.

\section{Literature Review}

The literature related to this research mainly includes two aspects: the optimal decisions of the supply chain involving logistics service providers and the optimal decisions of the multilevel supply chain.

\subsection{Optimal Decisions of the Supply Chain Involving Logistics} Service Providers. Focusing on the optimal decisions of the supply chain with the participation of logistics service providers, Li et al. [13] studied a supply chain composed of a retailer and a manufacturer. Logistics services can be provided in four situations: retailer, manufacturer, manufacturer outsourced by a third party, and retailer outsourced by a third party. The paper analyzes the optimal decisions of each subject under the leadership of the manufacturer. Zhang et al. [15] constructed a two-echelon supply chain composed of online retailers and logistics service providers and studied the optimal retail prices of products led by retailers and the optimal capacity expansion decisions of logistics service providers. On this basis, some scholars have expanded the two-level supply chain to three levels and closed-loop supply chain. For example, Giri et al. [14] constructed a closed-loop supply chain composed of retailers, manufacturers, and logistics companies, in which both the forward supply chain and the reverse supply chain are dual channels, and researched price and product recycling decisions under multiple power structures. Fan et al. [16] constructed a closed-loop supply chain composed of manufacturers, sellers, and third-party logistics providers and studied the optimal price and order quantity decisions based on centralized and decentralized decision-making modes under the leadership of manufacturers. Subrata et al. [17] researched the optimal pricing decisions of a dual-channel closed-loop supply chain composed of manufacturer, retailer, and a third party. Nikunja et al. [11] studied the optimal decisions of the three-level supply chain with the participation of logistics distribution service providers led by manufacturers and analyzed the optimal price and profit decisions of the two retailers under the circumstances of collusive decision, Cournot decision, master-slave decision, etc. Some scholars have also studied the optimal decisions of the supply chain around the characteristics of the product itself. For example, Yu and Xiao [12] built an agricultural product supply chain composed of retailers, suppliers, and logistics service providers based on the characteristics of agricultural products and studied the optimal price and logistics service level decisions under the two power structures led by logistics service providers and suppliers. Some scholars such as Yu [18] studied the optimal pricing decision of the dual-channel supply chain under the leadership of the supplier and TPL. Subrata [19] studied the optimal prices of a dual-channel supply chain composed of the manufacturer, the distributer, and the retailer in three different channel structures. On the basis of the above scholars' research on a single logistics service company, Gan [20] expanded it into two logistics service companies and studied the optimal decisions of the pharmaceutical supply chain led by the manufacturer with the participation of two competitive logistics service providers.

By systematically combing and reviewing the relevant literature, domestic and foreign scholars have studied the optimal decisions of the two-level supply chain, three-level supply chain, closed-loop supply chain, dual-channel supply chain, and closed-loop dual-channel supply chain involving a single logistics service provider. At the same time, they also studied the optimal decisions of the supply chain with the participation of a single logistics service provider and multiple competitive logistics service providers. However, most of the above studies are based on the perspective of manufacturers or retailers and do not involve the optimal decisions of the supply chain with the participation of two-echelon logistics service providers. They also lack a comparative research on the optimal decisions of the supply chain from the perspective of multiple power structures and multiple cooperative decision-making modes.

\subsection{Optimal Decisions of the Multilevel Supply Chain. The} research on optimal decisions of supply chain presents a research context from two levels to multiple levels. Shib [21] researched the optimal green quality and sales prices of the manufacturer and the retailer in a two-echelon supply chain. Izabela et al. [22] studied the optimal price and greening level decisions in a three-level green supply chain in both single and two-period setting. Subrata et al. [23] constructed a three-level supply chain with the participation of government, studied the optimal government subsidy strategy. The supply chain system participated by the two-echelon logistics service provider is composed of multiple decision makers at different levels, and it is a complex four-level supply chain essentially. This part focuses on the literature review around the decision optimization of multilevel supply chain.

In terms of research on optimal decisions in the multilevel supply chain, some scholars believe that the supply chain can achieve centralized decision, which is modeled with the goal of maximizing the total profit of the supply chain, minimizing costs, or optimizing service levels. For example, Khalifehzadeh et al. [24] constructed a four-level supply chain structure composed of suppliers, manufacturers, distribution service providers, and consumers and used a mixed-integer linear programming model to construct a network structure design scheme which minimizes the total operating cost of the supply chain. Abolfazl and Seyed [25] constructed a mathematical 
programming model with the goal of minimizing supply chain inventory costs, and studied the optimal inventory and inventory cycle decisions of a four-level supply chain. On this basis, Hamed et al. [26] constructed a multiobjective integer programming model with the smallest cost and the best service level to study the optimal product quality level decision of the four-level supply chain. Olivares et al. [27] used a mixed-integer linear programming model to study the location selection plan to maximize the profit of the four-level supply chain system from the perspective of distribution center location selection. Hasanov et al. [28] studied the optimal production and inventory decisions of a four-level closed-loop supply chain with the goal of minimizing the total cost of a closed-loop supply chain. The above studies on fourlevel supply chain decisions have not consider the influence of different power structures and cooperative decision-making modes on the optimal decisions and operational efficiency of the supply chain. Some scholars have also studied the optimal decisions of the four-level supply chain based on the perspective of decentralized decision-making mode. For example, Liu et al. [29] studied the optimal price decisions of the four-level supply chain composed of suppliers, manufacturers, distributors, and retailers. On this basis, Han et al. [30] further studied the quality control decisions of fourlevel supply chain led by manufacturers. Arnab et al. [31] studied the optimal price decisions of the five-level textile supply chain led by manufacturers and retailers. However, none of the above studies involve the situation led by logistics service providers, and there is also a lack of research about the influence of cooperative decision-making mode on the efficiency of supply chain operation and decision optimization with the participation of logistics service providers.

Based on the above literature research results, it can be concluded that at present, most scholars at home and abroad have studied the decision-making optimization problems of the supply chain with the participation of logistics service providers and the multilevel supply chain based on the perspective of a single power structure. Unfortunately, the two-echelon logistics service provider has not been considered in the whole supply chain system, and the influence of differences in power structures and cooperative decision-making modes are not introduced into the four-level supply chain with the participation of two-echelon logistics service providers. In view of this, this paper builds a supply chain structure model with the participation of the two-echelon logistics service providers based on the reality of layer-by-layer outsourcing in China's logistics industry. Based on multiple power structures, this paper tries to analyze the optimal decisions of four-level supply with the participation of the two-echelon logistics service providers under the different cooperative decision-making modes. It also analyzes the influence of the power structures on the optimal decisions of the supply chain, clarifies the optimal power structure of the entire supply chain system, and then explores the optimal cooperative decisionmaking mode for improving the operating efficiency of the supply chain system under the optimal power structure.

\section{Research Questions and Hypotheses}

3.1. Research Questions. The conceptual model of the fourlevel supply chain participated by the two-echelon logistics service provider is shown in Figure 2. Suppose that before the arrival of the sales season, the retailer places an order of $q$ to the upstream manufacturer based on the customer demand and the manufacturer produces according to the retailer's order quantity and then sells them to the retailer at the unit wholesale price $w$; consumers purchase products from the retailer at retail price $p$ through online channel; offline logistics services are provided by two-echelon logistics service providers formed by LSI and FLSP. The unit logistics service price that the retailer needs to pay to LSI is $p_{i}$, and the unit logistics service price that LSI needs to pay to FLSP is $p_{s}$; obviously, $p_{i}>p_{s}$. The logistics service level provided by FLSP is $e$. Consumers can weigh their purchasing decisions based on product retail price and logistics service level comprehensively.

In the four-level supply chain conceptual model shown in Figure 2, there are the following decision-making modes: PSC decentralized/LSSC decentralized decision-making mode (referred to as decentralized decision-making mode), two-party cooperative decision-making mode (including PSC decentralized/LSSC centralized decision-making mode, PSC centralized/LSSC decentralized decision-making mode, and PSC centralized/LSSC centralized decision-making mode), and tripartite cooperative decision-making mode, namely, cooperative decision-making mode between retailer and LSSC.

3.2. Research Hypothesis. This paper assumes that the four decision makers involved in supply chain system are risk-neutral and completely rational. At the same time, the information among the decision makers is symmetrical. Since the logistics services provision of the supply chain is ultimately reflected in the improvement of consumer experience and satisfaction, such as the lead time, which has an important impact on the service level of whole supply chain [32]. The logistics service level in this paper is only for consumers.

At the same time, because retailers sell products directly to consumers, they pay more attention to the logistics service impact of the entire supply chain on consumer satisfaction and their comprehensive experience. Therefore, this paper assumes that the logistics service price $p_{i}$ is borne by the retailer.

For the entire supply chain, product demand is not only affected by product retail price [33], but also by the level of logistics services [34]. Therefore, this paper assumes that the product demand function is $d=a-\beta p+k e$. At the same time, it is assumed that the customers' demand for the products is equal to the retailer's product order $q$; that is, the supply chain can fully meet customers' demand, where $a$ is the market size, $\beta$ is the sensitivity coefficient of product retail price, and $k$ is the sensitivity coefficient of logistics service level. The marginal logistics service cost of FLSP is $c_{s}$, and the logistics service cost related to the logistics service 


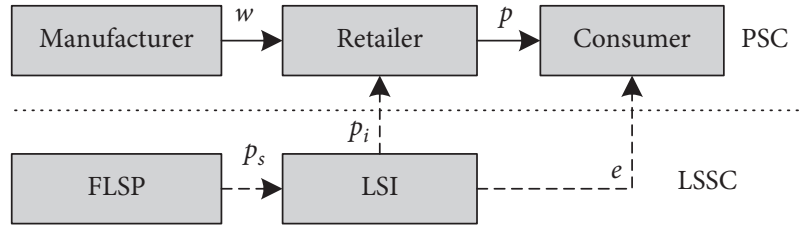

FIGURE 2: The conceptual model of the supply chain involving twoechelon logistics service providers.

level is $c(e)=e^{2} / 2$. Most literature studies generally use the form of a quadratic function to express the nonlinear relationship between service cost and service level, such as Jafar and Javad [35], Andy and Narendra [36], Hsieh and Liu [37], Jafar and Pooya [38], and Saeed et al. [39]. The relevant parameters and decision variables in the model are shown in Table 1.

Based on the above research hypothesis, the profit functions of each decision maker in the supply chain, the profit functions of PSC and LSSC, and the tripartite cooperative body (the cooperative body formed by the retailer and the LSSC) can be obtained as follows. Among them, manufacturer, retailer, LSI, FLSP, PSC, and LSSC are represented by subscripts $m, r, i, s, p$, and $l$, respectively, and tripartite cooperative body is represented by subscript $r l$ :

$$
\begin{aligned}
& \prod_{m}=\left(w-c_{m}\right)(a-\beta p+k e), \\
& \prod_{r}=\left(p-w-p_{i}\right)(a-\beta p+k e), \\
& \prod_{i}=\left(p_{i}-p_{s}\right)(a-\beta p+k e), \\
& \prod_{s}=\left(p_{s}-c_{s}\right)(a-\beta p+k e)-\frac{1}{2} e^{2}, \\
& \prod_{p}=\left(p-c_{m}-p_{i}\right)(a-\beta p+k e), \\
& \prod_{l}=\left(p_{i}-c_{s}\right)(a-\beta p+k e)-\frac{1}{2} e^{2}, \\
& \prod_{r l}=\left(p-w-c_{s}\right)(a-\beta p+k e)-\frac{1}{2} e^{2} .
\end{aligned}
$$

The total profit function of the supply chain system is

$$
\prod=\left(p-c_{m}-c_{s}\right)(a-\beta p+k e)-\frac{1}{2} e^{2} .
$$

\section{The Optimal Decisions under Different Power Structures}

This paper will focus on the power structure of manufacturer-led, retailer-led, and LSI-led and deeply study the optimal decisions of each decision maker in the supply chain based on a variety of decision-making modes. Among them, structures of manufacturer-led, retailer-led, and LSI-led are represented by superscripts $m, r$, and $i$, respectively. Decentralized decision-making mode, PSC decentralized/LSSC centralized decision-making mode, PSC centralized/LSSC decentralized decision-making mode, PSC centralized/ LSSC centralized decision-making mode, and tripartite cooperative decision-making mode are represented by superscripts $d d, d c, c d, c c$, and $t$, respectively.

\subsection{The Optimal Decisions Led by Manufacturer}

4.1.1. Decentralized Decision-Making Mode. The decision sequence of the decentralized decision-making mode led by manufacturer is as follows: firstly, the manufacturer decides the product wholesale price $w$, then LSI decides the logistics service price $p_{i}$, and FLSP decides the logistics service level $e$ and the logistics service price $p_{s}$. Finally, the retailer decides the retail price $p$ of the product.

First, the derivative of $\Pi_{r}^{m d d}$ to $p$ is obtained by the inverse induction method, since $\partial^{2} \Pi_{r}^{m d d} / \partial p^{2}=-2 \beta<0$, so $\Pi_{r}^{m d d}$ is a quadratic concave function of $p$, making $\partial \Pi_{r}^{m d d} / \partial p=0$, and we obtain

$$
p^{m d d}=\frac{a+k e+\beta w+\beta p_{i}}{2 \beta} .
$$

Substituting (9) into $\Pi_{s}^{m d d}$, since $\Pi_{s}^{m d d}$ is jointly negative for $p_{s}$ and $e$, the Hessian matrix is as follows:

$$
H\left(p_{s}, e\right)=\left[\begin{array}{cc}
\frac{\partial^{2} \Pi_{s}^{m d d}}{\partial p_{s}^{2}} & \frac{\partial^{2} \Pi_{s}^{m d d}}{\partial p_{s} \partial e} \\
\frac{\partial^{2} \Pi_{s}^{m d d}}{\partial e \partial p_{s}} & \frac{\partial^{2} \Pi_{s}^{m d d}}{\partial^{2} e}
\end{array}\right]=\left[\begin{array}{cc}
-\frac{\beta}{2} & \frac{k}{2} \\
\frac{k}{2} & -1
\end{array}\right] .
$$

The above Hessian matrix satisfies the negative definite criterion, when it satisfies $2 \beta-k^{2}>0$.

According to $\partial \Pi_{s}^{m d d} / \partial p_{s}=0, \partial \Pi_{s}^{m d d} / \partial e=0$, it can be concluded that

$$
\begin{aligned}
e^{m d d} & =\frac{k\left(a-\beta w-\beta p_{i}\right)}{2 \beta-k^{2}}, \\
p_{s}^{m d d} & =\frac{2 a-2 \beta w-2 \beta p_{i}+2 \beta c_{s}-k^{2} c_{s}}{2 \beta-k^{2}} .
\end{aligned}
$$

Substituting (9)-(12) into $\Pi_{i}^{\text {mdd }}$, since $\partial^{2} \Pi_{i}^{\text {mdd }} / \partial p_{i}^{2}=$ $\left(-2 \beta^{2}\left(4 \beta-k^{2}\right)\right) /\left(2 \beta-k^{2}\right)^{2}<0$, so $\Pi_{i}^{\text {mdd }}$ is a quadratic concave function of $p_{i}$, let $\partial \Pi_{i}^{m d d} / \partial p_{i}=0$, and we obtain

$$
p_{i}^{m d d}=\frac{\left(6 \beta-k^{2}\right)(a-\beta w)+\beta c_{s}\left(2 \beta-k^{2}\right)}{2 \beta\left(4 \beta-k^{2}\right)} .
$$

Substituting (9)-(13) into $\Pi_{m}^{m d d}$, since $\partial^{2} \Pi_{m}^{m d d} / \partial w^{2}=$ $-2 \beta<0$, so $\Pi_{i}^{m d d}$ is a quadratic concave function of $w$, making $\partial \Pi_{m}^{m d d} / \partial w=0$, the optimal product wholesale price is as follows: 
TABLE 1: Parameters and decision variables in the model.

\begin{tabular}{lccc}
\hline Parameters & Implication & Decision variables & Implication \\
\hline$c_{m}$ & Marginal production cost of manufacturer & $w$ & Product wholesale price \\
$c_{s}$ & Marginal logistics cost of FLSP & $p_{i}$ & Logistics services price paid by retailer \\
$a$ & Market capacity & $e$ & Logistics service level \\
$\beta$ & Sensitivity coefficient of product retail price & $p$ & Product retail price \\
$k$ & Sensitivity coefficient of logistics service level & $p_{s}$ & Logistics services price paid by LSI \\
\hline
\end{tabular}

$$
w^{m d d^{*}}=\frac{a-\beta c_{m}-\beta c_{s}}{2 \beta} .
$$

Due to $w^{m d d^{*}}-c_{m} \geq 0$, so $a-\beta c_{m}-\beta c_{s} \geq 0$.

Substituting (14) into (9)-(13), the optimal decision variables are as follows:

$$
\begin{aligned}
e^{m d d^{*}} & =\frac{k\left(a-\beta c_{m}-\beta c_{s}\right)}{4\left(4 \beta-k^{2}\right)}, \\
p^{m d d^{*}} & =\frac{\left(15 \beta-3 k^{2}\right)\left(a-\beta c_{m}-\beta c_{s}\right)}{4 \beta\left(4 \beta-k^{2}\right)}+c_{m}+c_{s}, \\
p_{i}^{m d d^{*}} & =\frac{\left(a-\beta c_{m}-\beta c_{s}\right)\left(6 \beta-k^{2}\right)}{4 \beta\left(4 \beta-k^{2}\right)}+c_{s}, \\
p_{s}^{m d d^{*}} & =\frac{a-\beta c_{m}-\beta c_{s}}{2\left(4 \beta-k^{2}\right)}+c_{s} .
\end{aligned}
$$

Substituting (15) and (16) into $d=a-\beta p+k e$, we can obtain the optimal product demand:

$$
d^{m d d^{*}}=\frac{\beta\left(a-\beta c_{m}-\beta c_{s}\right)}{4\left(4 \beta-k^{2}\right)} .
$$

Substituting (14)-(18) into (1)-(8), the optimal profit functions of each decision maker can be obtained as shown in Table 2; among them, $2 \beta-k^{2}>0$ and $a-\beta c_{m}-\beta c_{s} \geq 0$.

\subsubsection{PSC Decentralized/LSSC Centralized Decision-Making} Mode. The decision sequence of the PSC decentralized/ LSSC centralized decision-making mode led by the manufacturer is as follows: firstly, the manufacturer decides the wholesale price $w$ of the product, and then the LSSC decides the logistics service price $p_{i}$ and the logistics service level $e$. Finally, the retailer decides the retail price $p$ of the product. Using the reverse induction method, the optimal solutions can be obtained as shown in Table 2; among them, $4 \beta-$ $k^{2}>0$ and $a-\beta c_{m}-\beta c_{s} \geq 0$. The specific calculation process is the same as above, which is omitted here.

\subsubsection{PSC Centralized/LSSC Decentralized Decision-Making} Mode. The decision sequence of the PSC centralized/LSSC decentralized decision-making mode led by the manufacturer is as follows: firstly, PSC decides the retail price of the product $p$, LSI decides the logistics service price $p_{i}$, and finally, FLSP decides the logistics service level $e$ and the logistics service price $p_{s}$. Using the reverse induction method, the optimal solutions can be obtained as shown in Table 2; among them, $\beta-k^{2}>0$ and $a-\beta c_{m}-\beta c_{s} \geq 0$.

4.1.4. PSC Centralized/LSSC Centralized Decision-Making Mode. The decision sequence of the PSC centralized/LSSC centralized decision-making mode led by the manufacturer is as follows: firstly, PSC decides the retail price of the product $p$, and then LSSC decides the logistics service price $p_{i}$ and the logistics service level $e$. Using the reverse induction method, the optimal solutions can be obtained as shown in Table 2; among them, $\beta-k^{2}>0$ and $a-\beta c_{m}-\beta c_{s} \geq 0$.

4.1.5. Tripartite Cooperative Decision-Making Mode. The decision sequence of the tripartite cooperative decisionmaking mode led by the manufacturer is as follows: firstly, the manufacturer decides the wholesale price $w$ of the product, followed by a tripartite cooperative body composed of retailers and LSSC jointly decides the product retail price $p$ and logistics service level $e$. Using the reverse induction method, the optimal solutions can be obtained as shown in Table 2; among them, $2 \beta-k^{2}>0$ and $a-\beta c_{m}-\beta c_{s} \geq 0$.

\subsection{The Optimal Decisions Led by Retailer}

4.2.1. Decentralized Decision-Making Mode. The decision sequence of the decentralized decision-making mode led by the retailer is as follows: firstly, the retailer decides the retail price $p$ of the product, the manufacturer decides the wholesale price $w$ of the product, then LSI decides the logistics service price $p_{i}$. Finally, FLSP decides the logistics service level $e$ and logistics service price $p_{s}$. The optimal solutions are shown in Table 3 ; among them, $\beta-k^{2}>0$ and $a-\beta c_{m}-\beta c_{s} \geq 0$.

\subsubsection{PSC Decentralized/LSSC Centralized Decision-Making} Mode. The decision sequence of the PSC decentralized/ LSSC centralized decision-making mode led by the retailer is as follows: firstly, the retailer decides the retail price $p$ of the product, the manufacturer decides the wholesale price $w$ of the product, and then the LSSC decides the logistics service price $p_{i}$ and the logistics service level $e$. The optimal solutions are shown in Table 3; among them, $\beta-k^{2}>0$ and $a-\beta c_{m}-\beta c_{s} \geq 0$.

4.2.3. PSC Centralized/LSSC Decentralized and PSC Centralized/LSSC Centralized Decision-Making Mode. The optimal decisions of the PSC centralized/LSSC 


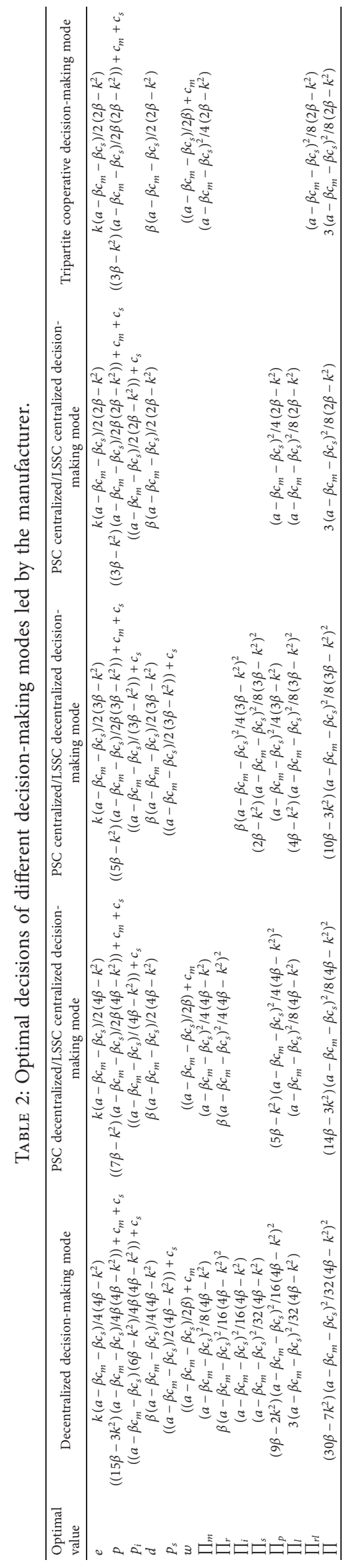




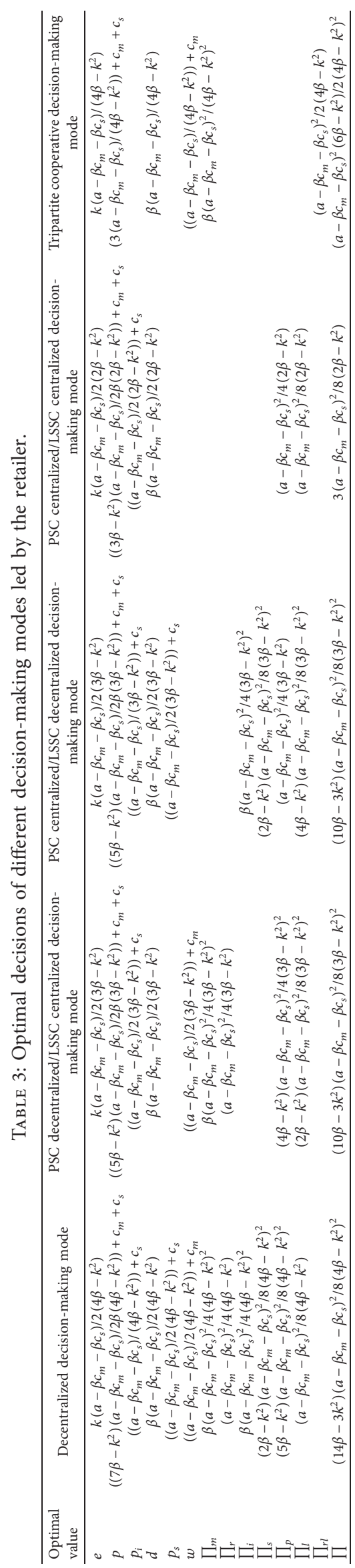


decentralized decision-making mode and the PSC centralized/LSSC centralized decision-making mode led by the retailer are consistent with the optimal decisions led by the manufacturer, as shown in Table 3.

4.2.4. Tripartite Cooperative Decision-Making Mode. The decision sequence of the tripartite cooperative decisionmaking mode is as follows: firstly, a tripartite cooperative body composed of retailers and LSSC jointly decides the retail price $p$ and logistics service level $e$ of the product, and then the manufacturer decides the wholesale price $w$ of the product. The optimal solutions are shown in Table 3; among them, $4 \beta-k^{2}>0$ and $a-\beta c_{m}-\beta c_{s} \geq 0$.

\subsection{The Optimal Decisions Led by LSI}

4.3.1. Decentralized Decision-Making Mode. The decision sequence of the decentralized decision-making mode led by LSI is as follows: firstly, LSI decides the logistics service price $p_{i}$, FLSP decides the logistics service level $e$ and the logistics service price $p_{s}$, then the manufacturer decides the product wholesale price $w$, and finally, the retailer decides the product retail price $p$. The optimal solutions are shown in Table 4; among them, $4 \beta-k^{2}>0$ and $a-\beta c_{m}-\beta c_{s} \geq 0$.

\subsubsection{PSC Decentralized/LSSC Centralized Decision-Making} Mode. The decision sequence of the PSC decentralized/ LSSC centralized decision-making mode led by LSI is as follows: firstly, LSSC decides the logistics service price $p_{i}$ and the logistics service level $e$, and then, the manufacturer decides the wholesale price $w$ of the product. Finally, the retailer decides the retail price $p$ of the product. The optimal solutions are shown in Table 4; among them, $8 \beta-k^{2}>0$ and $a-\beta c_{m}-\beta c_{s} \geq 0$.

\subsubsection{PSC Centralized/LSSC Decentralized Decision-Making} Mode. The decision sequence of the PSC centralized/LSSC decentralized decision-making mode led by LSI is as follows: firstly, LSI decides the logistics service price $p_{i}$, then FLSP decides the logistics service level $e$ and the logistics service price $p_{s}$, and finally, PSC decides the retail price $p$ of the product. The optimal solutions are shown in Table 4; among them, $2 \beta-k^{2}>0$ and $a-\beta c_{m}-\beta c_{s} \geq 0$.

4.3.4. PSC Centralized/LSSC Centralized Decision-Making Mode. The decision sequence of the PSC centralized/LSSC centralized decision-making mode led by LSI is as follows: firstly, LSSC decides the logistics service price $p_{i}$ and the logistics service level $e$, followed by the PSC decides product retail price $p$. The optimal solutions are shown in Table 4; among them, $4 \beta-k^{2}>0$ and $a-\beta c_{m}-\beta c_{s} \geq 0$.

4.3.5. Tripartite Cooperative Decision-Making Mode. The optimal decisions of the tripartite cooperative decisionmaking mode led by LSI is the same as the optimal decisions led by retailer, as shown in Table 4 .

\section{Impact of the Difference in Power Structure on the Optimal Decisions of the Supply Chain}

Proposition 1. In the decentralized decision-making mode, the retailer-led supply chain has the largest total profit, the smallest product retail price, the highest logistics service level, and the largest consumer surplus, while the LSI-led supply chain has the smallest total profit and logistics service level, and product retail price is the highest and the consumer surplus is the smallest.

Proof according to the calculation results in Tables $2-4$, we can get as follows: $\Pi^{r d d *}=\left(14 \beta-3 k^{2}\right)\left(a-\beta c_{m}-\beta c_{s}\right)^{2}$ $18\left(4 \beta-k^{2}\right)^{2}, \quad \Pi^{m d d *}=\left(30 \beta-7 k^{2}\right) \quad\left(a-\beta c_{m}-\beta c_{s}\right)^{2} / 32$ $\left(4 \beta-k^{2}\right)^{2}$, and $\Pi^{i d d *}=\left(30 \beta-3 k^{2}\right)\left(a-\beta c_{m}-\beta c_{s}\right)^{2} / 8$ $\left(8 \beta-k^{2}\right)^{2}$, due to $\beta-k^{2}>0$, so $\Pi^{r d d *}>\Pi^{m d d *}>\Pi^{i d d *}$. This shows that under the decentralized decision-making mode, the retailer-led supply chain has the largest total profit, which is consistent with the research conclusion of Giri and Sarker [40]; that is to say, when each decision maker of the supply chain system adopts decentralized decisionmaking mode, the retailer-led operation of the entire supply chain can maximize the benefit of the entire supply chain.

Due to $p^{r d d *}=\left(\left(7 \beta-k^{2}\right)\left(a-\beta c_{m}-\beta c_{s}\right) / 2 \beta\left(4 \beta-k^{2}\right)\right)+$ $c_{m}+c_{s}, p^{m d d *}=\left(\left(15 \beta-3 k^{2}\right)\left(a-\beta c_{m}-\beta c_{s}\right) / 4 \beta\left(4 \beta-k^{2}\right)\right)+$ $c_{m}+c_{s}, \beta-k^{2}>0$, so $\left(\left(\left(7 \beta-k^{2}\right)\left(a-\beta c_{m}-\beta c_{s}\right) / 2 \beta(4 \beta-\right.\right.$ $\left.\left.\left.k^{2}\right)\right) /\left(\left(\left(15 \beta-3 k^{2}\right)\left(a-\beta c_{m}-\beta c_{s}\right)\right) /\left(4 \beta\left(4 \beta-k^{2}\right)\right)\right)\right)=14 \beta-$ $2 k^{2} / 15 \beta-3 k^{2}<1$, so $p^{r d d *}<p^{m d d *}$. And due to $p^{i d d *}=$ $\left(\left(\left(60 \beta^{2}-19 \beta k^{2}+k^{4}\right)\left(a-\beta c_{m}-\beta c_{s}\right)\right) /\left(2 \beta\left(4 \beta-k^{2}\right)(8 \beta-\right.\right.$ $\left.\left.\left.k^{2}\right)\right)\right)+c_{m}+c_{s}, \quad\left(\left(\left(60 \beta^{2}-19 \beta k{ }^{2}+k^{4}\right)\left(a-\beta c_{m}-\beta c_{s}\right)\right) /\right.$ $\left.\left(2 \beta\left(4 \beta-k^{2}\right)\left(8 \beta-k^{2}\right)\right)\right) /\left(\left(15 \beta-3 \quad k^{2}\right)\left(a-\beta c_{m}-\beta c_{s}\right)\right) /$ $\left.\left(4 \beta\left(4 \beta-k^{2}\right)\right)\right)>1$, so, $p^{m d d *}<p^{i d d *}$, and we can get that $p^{r d d *}<p^{m d d *}<p^{i d d *}$.

In the same way, due to $e^{r d d *}=k\left(a-\beta c_{m}-\beta c_{s}\right)$ $12\left(4 \beta-k^{2}\right), e^{m d d *}=k\left(a-\beta c_{m}-\beta c_{s}\right) / 4\left(4 \beta-k^{2}\right), e^{i d d *}=$ $k\left(a-\beta c_{m}-\beta c_{s}\right) / 2\left(8 \beta-k^{2}\right)$, we can get $e^{r d d *}>$ $e^{m d d *}>e^{i d d *}$.

Drawing lessons from the calculation method of consumer surplus by $\mathrm{Yu}$ and Xiao [12], the consumer surplus can be calculated as follows: $c s=\int_{p_{\min }}^{p_{\max }} d d p=\int_{(a+k e-d) / \beta}$ $(a+k e) / \beta(a-\beta p+k e) \mathrm{d} p=(a-\beta p+k e)^{2} / 2 \beta$. The retailer-led logistics service level is the highest, and the product retail price is the lowest, so its consumer surplus is the largest. Similarly, the consumer surplus is the smallest under the LSI-led structure.

Thus, in the supply chain system with the participation of two-echelon logistics service providers, the strength of retailer should be gradually strengthened, and the retailer should lead the whole supply chain. This is because the retailer has direct business contacts and business relationships with the upstream manufacturer and LSSC that provide logistics services for them. It is more convenient to establish trust mechanisms and cooperative relationships with these decision makers, and it is also convenient to achieve the resource integration of the entire supply chain. While the business relationship between manufacturer and 
LSSC is relatively loose, so the advantages of retailers' domination are more prominent.

Proposition 2. Under different power structures, compared with the two-party cooperative decision-making modes of PSC centralized/LSSC decentralized and PSC decentralized/LSSC centralized, the total supply chain profit, logistics service level, product demand, and consumer surplus of the PSC centralized/LSSC centralized decision-making mode are higher.

Proof under the leadership of the retailer, the total profit of the supply chain for PSC centralized/LSSC decentralized decision-making mode is $\Pi^{r c d *}=\left(10 \beta-3 k^{2}\right)\left(a-\beta c_{m}-\right.$ $\left.\beta c_{s}\right)^{2} / 8\left(3 \beta-k^{2}\right)^{2}$. The total profit of the supply chain for PSC decentralized /LSSC centralized decision-making mode is $\Pi^{r d c *}=\left(10 \beta-3 k^{2}\right)\left(a-\beta c_{m}-\beta c_{s}\right)^{2} / 8\left(3 \beta-k^{2}\right)^{2}$, while the total profit of the supply chain of the PSC centralized/ LSSC centralized decision-making mode is $\Pi^{r c c *}=3(a-$ $\left.\beta c_{m}-\beta c_{s}\right)^{2} / 8\left(2 \beta-k^{2}\right)$, due to $\beta-k^{2}>0$, so $\Pi^{r c c *} / \Pi^{r c d *}=$ $\left(24\left(3 \beta-k^{2}\right)^{2} / 8\left(2 \beta-k^{2}\right)\left(10 \beta-3 k^{2}\right)\right)>1, \quad \Pi^{r c c *} / \Pi^{r d c *}=$ $24\left(3 \beta-k^{2}\right)^{2} / 8\left(2 \beta-k^{2}\right)\left(10 \beta-3 k^{2}\right)>1$, and $\Pi^{r c c *}>\Pi^{r c d *}$, $\Pi^{r c c *}>\Pi^{r d c *}$.

The same conclusions can be obtained that

$$
\begin{aligned}
& e^{r c c^{*}}=\frac{k\left(a-\beta c_{m}-\beta c_{s}\right)}{2\left(2 \beta-k^{2}\right)}>e^{r c d^{*}}=\frac{k\left(a-\beta c_{m}-\beta c_{s}\right)}{2\left(3 \beta-k^{2}\right)}, \\
& e^{r c c^{*}}=\frac{k\left(a-\beta c_{m}-\beta c_{s}\right)}{2\left(2 \beta-k^{2}\right)}>e^{r d c^{*}}=\frac{k\left(a-\beta c_{m}-\beta c_{s}\right)}{2\left(3 \beta-k^{2}\right)}, \\
& d^{r c c^{*}}=\frac{\beta\left(a-\beta c_{m}-\beta c_{s}\right)}{2\left(2 \beta-k^{2}\right)}>d^{r c d^{*}}=\frac{\beta\left(a-\beta c_{m}-\beta c_{s}\right)}{2\left(3 \beta-k^{2}\right)}, \\
& d^{r c c^{*}}=\frac{\beta\left(a-\beta c_{m}-\beta c_{s}\right)}{2\left(2 \beta-k^{2}\right)}>d^{r d c^{*}}=\frac{\beta\left(a-\beta c_{m}-\beta c_{s}\right)}{2\left(3 \beta-k^{2}\right)}, \\
& p^{r c c^{*}}=\frac{\left(3 \beta-k^{2}\right)\left(a-\beta c_{m}-\beta c_{s}\right)}{2 \beta\left(2 \beta-k^{2}\right)}+c_{m}+c_{s}<p^{r c d^{*}}=\frac{\left(5 \beta-k^{2}\right)\left(a-\beta c_{m}-\beta c_{s}\right)}{2 \beta\left(3 \beta-k^{2}\right)}+c_{m}+c_{s}, \\
& p^{r c c^{*}}=\frac{\left(3 \beta-k^{2}\right)\left(a-\beta c_{m}-\beta c_{s}\right)}{2 \beta\left(2 \beta-k^{2}\right)}+c_{m}+c_{s}<p^{r d c^{*}}=\frac{\left(5 \beta-k^{2}\right)\left(a-\beta c_{m}-\beta c_{s}\right)}{2 \beta\left(3 \beta-k^{2}\right)}+c_{m}+c_{s} .
\end{aligned}
$$

So, $c s^{r c c *}>c s^{r c d *}, c s^{r c c *}>c s^{r d c *}$.

That is to say, compared with the two-party cooperative decision-making modes of PSC centralized/LSSC decentralized and PSC decentralized/LSSC centralized, under the domination of retailers, the PSC centralized/ LSSC centralized decision-making mode has higher total supply chain profits, logistics service level, product demand, and consumer surplus.

Similarly, it can also be proved that there are consistent research conclusions under the leadership of manufacturer and LSI. That is, under different power structures, compared with other cooperation modes, the total supply chain profit, logistics service level, and consumer surplus of the PSC centralized/LSSC centralized decision-making mode are higher. So, the managerial implication is PSC and LSSC should adopt a centralized decision-making mode, respectively, in the two-party cooperative decision-making mode, from the perspective of maximizing the total profit of the system and maximizing the utility of consumers.

The higher the degree of cooperation among the decision maker in the system, the better the total profit and service level of the system, and the greater the consumer surplus. Since logistics activities run through the entire supply chain and it is an important carrier connecting various companies in the supply chain, LSSC should provide PSC with integrated supply chain services as a long-term partner and a strategic partner of PSC. Only in this way can the manufacturers and retailers in the supply chain system be effectively combined to achieve a higher level of logistics services and pursue higher product sales and profit growth.

Proposition 3. Under different power structures, in the two-party cooperative decision-making mode, the PSC centralized/LSSC centralized decision-making mode is the optimal cooperative decision-making mode. 


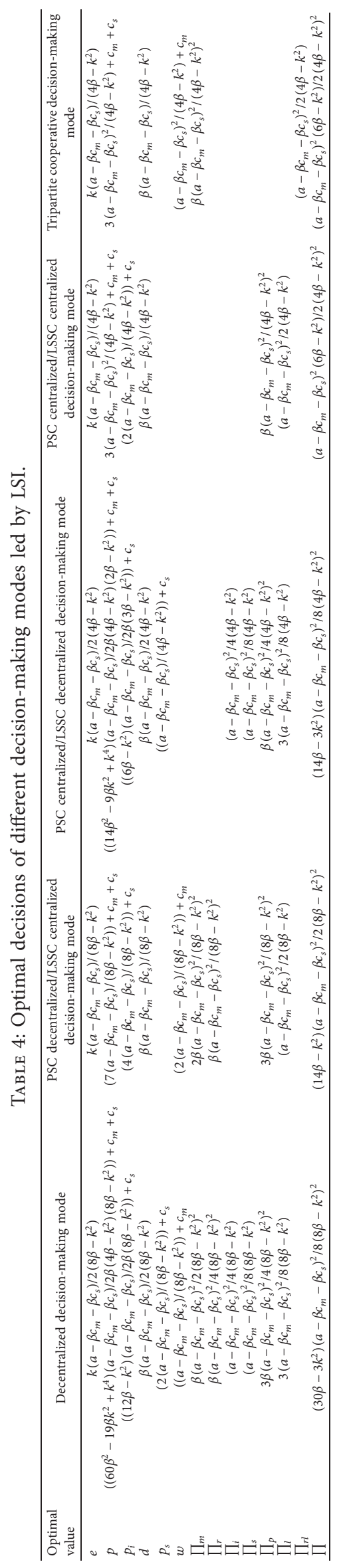


Proof:. under the leadership of the retailer, if the LSSC adopts the decentralized decision-making mode, at this time, the profit of PSC's adoption of decentralized decisionmaking mode is $\Pi_{p}^{r d d *}=\left(5 \beta-k^{2}\right)\left(a-\beta c_{m}-\beta c_{s}\right)^{2} / 4(4 \beta-$ $\left.k^{2}\right)^{2}$ and the profit of its adoption of centralized decisionmaking mode is $\Pi_{p}^{r c d *}=\left(a-\beta c_{m}-\beta c_{s}\right)^{2} / 4\left(3 \beta-k^{2}\right)$, due to $\beta-k^{2}>0$, so $\Pi_{p}^{r c d *} / \Pi_{p}^{r d d *}=\left(\left(\left(a-\beta c_{m}-\beta c_{s}\right)^{2} \quad / 4(3 \beta-\right.\right.$ $\left.\left.\left.k^{2}\right)\right) /\left(\left(5 \beta-k^{2}\right)\left(a-\beta c_{m}-\beta c_{s}\right)^{2} / 4\left(4 \beta-k^{2}\right)^{2}\right)\right)=\left(\left(4 \beta-k^{2}\right)^{2}\right.$ / $\left.\left(3 \beta-k^{2}\right)\left(5 \beta-k^{2}\right)\right)>1$, Therefore, the PSC will adopt a centralized decision-making mode; at the same time, if the LSSC adopts a centralized decision-making mode, the profit of PSC's adoption of the decentralized decision-making mode is $\Pi_{p}^{r d c *}=\left(4 \beta-k^{2}\right)\left(a-\beta c_{m}-\beta c_{s}\right)^{2} / 4\left(3 \beta-k^{2}\right)^{2}$, the profit of its adoption of centralized decision-making mode is $\Pi_{p}^{r c c *}=\beta\left(a-\beta c_{m}-\beta c_{s}\right)^{2} /\left(4 \beta-k^{2}\right)^{2}$, due to $\Pi_{p}^{r c c *} /$ $\Pi_{p}^{p d c *}=4 \beta\left(3 \beta-k^{2}\right)^{2} /\left(4 \beta-k^{2}\right)^{3}>1$, Therefore, PSC will adopt a centralized decision-making mode; that is, no matter what strategy LSSC adopts, for PSC, centralized decisionmaking mode is its dominant strategy.

When PSC chooses centralized decision-making mode, the profit of LSSC's adoption of centralized decision is $\Pi_{l}^{r c c *}=\left(a-\beta c_{m}-\beta c_{s}\right)^{2} / 8\left(2 \beta-k^{2}\right)$ and the profit of its adoption of decentralized decision-making mode is $\Pi_{l}^{r c d *}=\left(4 \beta-k^{2}\right)\left(a-\beta c_{m}-\beta c_{s}\right)^{2} / 8\left(3 \beta-k^{2}\right)^{2}$, and we can see that $\Pi_{l}^{r c c *} / \Pi_{l}^{r c d *}==\left(\left(3 \beta-k^{2}\right)^{2} / \quad\left(2 \beta-k^{2}\right)(4 \beta-\right.$ $\left.\left.k^{2}\right)\right)>1$. That is to say, for LSSC, centralized decisionmaking mode is its dominant strategy.

The same can be proved that under different power structures, when the PSC or LSSC in the system adopts a cooperative strategy, the following research conclusions exist: $\Pi_{p}^{c c *}>\Pi_{p}^{d c *}, \Pi_{p}^{c d *}>\Pi_{p}^{d d *}$. That is, no matter what strategy PSC adopts, LSSC will choose centralized decision-making mode. Therefore, PSC centralized/LSSC centralized decision-making mode is the optimal cooperative decision-making mode. The managerial implication is, as for the decision makers of PSC and LSSC, each decision maker should adopt a cooperative strategy in order to maximize the benefits of their respective partners.

The logistics service supply chain composed of logistics service integrator and functional logistics service provider intervenes in the operation of the product supply chain through providing logistics services. It belongs to a subordinate position, so it must be through centralized decision-making mode to enhance the service ability of the entire system, so as to ensure the profit of the logistics service supply chain. That is to say, it is necessary to improve the overall competitive advantage of logistics services by integrating relevant logistics service resources.

Proposition 4. Under the leadership of the manufacturer, compared with the tripartite cooperative decision-making mode, the manufacturer is more inclined to cooperate with the retailer, thus forming a PSC centralized decision-making mode.

According to the calculation results in Table 2, the total profit of PSC in the PSC centralized/LSSC centralized decision-making mode under the leadership of the manufacturer is $\Pi_{p}^{m c c *}=\left(a-\beta c_{m}-\beta c_{s}\right)^{2} / 4\left(2 \beta-k^{2}\right)$ and the total profit of manufacturer under the tripartite cooperative decision-making mode is $\Pi_{m}^{m t *}=\left(a-\beta c_{m}-\beta c_{s}\right)^{2} /$ $4\left(2 \beta-k^{2}\right)$, due to $\Pi_{p}^{m c c *}=\Pi_{m}^{m t *}$; that is to say, for the supply chain led by the manufacturer, the profit of the PSC partnership formed by the manufacturer and the retailer is equal to the profit of the manufacturer under the tripartite cooperative decision-making mode. Since the manufacturer's profit in the PSC decentralized/LSSC decentralized decision is $\Pi_{m}^{m d d *}=\left(a-\beta c_{m}-\beta c_{s}\right)^{2} / 8\left(4 \beta-k^{2}\right), \Pi_{m}^{m d d *}<$ $\Pi_{p}^{m c c *}=\Pi_{m}^{m t^{*}}$; that is to say, for the manufacturer, the profit under the decentralized decision-making mode is lower. In order to improve its own profit level, the manufacturer will give priority to actively forming a PSC cooperative body with the retailer, rather than passively waiting for the retailer to form a cooperative body with LSSC. This conclusion is consistent with Neha [41], the collaboration of vendor and buyer is profitable for the participating members. Therefore, the managerial implication is that the manufacturer should cooperate with retailer to form a PSC centralized decisionmaking mode under the leadership of the manufacturer in all cooperative decision-making modes.

Proposition 5. Under the leadership of the retailer, the strategy of forming a PSC partnership by retailer and manufacturer is better than the strategy of building a cooperation mode between retailer and LSSC, whether it is from the perspective of retailer, consumer, or the entire supply chain.

According to the calculation results in Table 3, the total profit of PSC in the PSC centralized/LSSC centralized decision-making mode is $\Pi_{p}^{r c c *}=\left(a-\beta c_{m}-\beta c_{s}\right)^{2} / 4\left(2 \beta-k^{2}\right)$, while the total profit of tripartite cooperation body under the tripartite cooperative decision-making mode is $\Pi_{r l}^{r t *}=(a-$ $\left.\beta c_{m}-\beta c_{s}\right)^{2} / 2\left(4 \beta-k^{2}\right)$, due to $\Pi_{p}^{r c c *}>\Pi_{r l}^{r t *}$; that is to say, for the supply chain led by the retailer, the retailer is more inclined to cooperate with the manufacturer, so that the total profit of forming a PSC cooperative body is greater.

At the same time, according to the calculation results in Table 3, we can get as follows: $e^{r c c *}=k\left(a-\beta c_{m}-\beta c_{s}\right) /$ $2\left(2 \beta-k^{2}\right) e^{r t *}=k\left(a-\beta c_{m}-\beta c_{s}\right) /\left(4 \beta-k^{2}\right)$, so $e^{r c c *}>e^{r t *}$; $p^{r c c *}=\left(3 \beta-k^{2}\right)\left(a-\beta c_{m}-\beta c_{s}\right) / 2 \beta\left(2 \beta-k^{2}\right)+c_{m}+c_{s}$ and $p^{r t *}=3\left(a-\beta c_{m}-\beta c_{s}\right) / 4 \beta-k^{2}+c_{m}+c_{s}$, so $p^{r c c *}<p^{r t *}$. Combined with the above formula for calculating consumer surplus, it can be obtained that $c s^{r c c *}>c s^{r * *}$.

At the same time, under the leadership of the retailer, $\Pi^{r c c *}=3\left(a-\beta c_{m}-\beta c_{s}\right)^{2} / 8\left(2 \beta-k^{2}\right)$ and $\Pi^{r t *}=(6 \beta-$ $\left.k^{2}\right)\left(a-\beta c_{m}-\beta c_{s}\right)^{2} / 2\left(4 \beta-k^{2}\right)^{2}$, due to $\beta-k^{2}>0$, so $\Pi^{r c c *}$ / $\Pi^{r t *}=\left(3\left(4 \beta-k^{2}\right)^{2} / 4\left(2 \beta-k^{2}\right)\left(6 \beta-k^{2}\right)\right)>1$; that is to say, under the leadership of the retailer, the total supply chain profit of the tripartite cooperative decision-making mode is less than the total supply chain profit of the PSC centralized/LSSC centralized decision-making mode.

Therefore, whether from the perspective of the retailer, the consumer, or the entire supply chain, the strategy of forming a PSC partnership by the retailer and manufacturer is better than the strategy of building a cooperation mode between the retailer and LSSC. So, the managerial 
implication is that the retailer should cooperate with the manufacturer under the leadership of the retailer in all cooperative decision-making modes.

Proposition 6. Under the leadership of LSI, compared to the tripartite cooperative decision-making mode, LSI is more inclined to cooperate with FLSP, thus forming the LSSC centralized decision-making mode.

According to the calculation results in Table 4, under the leadership of LSI, the total profit of LSSC in PSC centralized/LSSC centralized decision-making mode is $\Pi_{l}^{i c c *}=\left(a-\beta c_{m}-\beta c_{s}\right)^{2} / 2\left(4 \beta-k^{2}\right)$, while the total profit of tripartite cooperation body under the tripartite cooperative decision-making mode is $\Pi_{r l}^{i t *}=\left(a-\beta c_{m}-\right.$ $\left.\beta c_{s}\right)^{2} / 2\left(4 \beta-k^{2}\right)$, due to $\Pi_{l}^{i c c *}=\Pi_{r l}^{i t *}$; that is to say, for the supply chain led by LSI, the total profit of LSSC which is constructed by LSI and FLSP is equal to the total profit of tripartite cooperative body which is constructed by LSI, FLSP, and retailer. Therefore, LSI is more inclined to cooperate with FLSP rather than forming a tripartite cooperative body, such cooperative relationship is easier to establish and maintain. Therefore, the managerial implication is that LSI and FLSP will build an LSSC centralized decision-making mode under the leadership of LSI.

Combining the research results of comprehensive Propositions 3-6, we can get as follows: under different power structures, the PSC centralized/LSSC centralized decision-making mode is the dominant strategy. At this time, the total profit and consumer surplus of the entire supply chain are the largest, the profit of each decision maker is the largest, and the operation efficiency of supply chain is the highest.

Proposition 7. Compared with the two power structures of manufacturer-led and LSI-led, whether it is from the perspective of maximizing the total profit of the supply chain or maximizing consumer surplus, or from the perspective of different decision-making modes, the entire supply chain dominated by retailers is the optimal power structure.

Proof:. according to the conclusions of the above research, under different power structures, the PSC centralized/LSSC centralized decision-making mode is the dominant strategy. Under the PSC centralized/LSSC centralized decisionmaking mode, the total profit of the retailer-led supply chain is equal to the total profit of the manufacturer-led supply chain $\Pi^{r c c *}=3\left(a-\beta c_{m}-\beta c_{s}\right)^{2} / 8\left(2 \beta-k^{2}\right)$, and the total profit of the LSI-led supply chain is $\Pi^{i c c *}=\left(\left(a-\beta c_{m}-\right.\right.$ $\left.\left.\beta c_{s}\right)^{2}\left(6 \beta-k^{2}\right)\right) /\left(2\left(4 \beta-k^{2}\right)^{2}\right)$; due to $\beta-k^{2}>0$, we can get $\Pi^{r c c *} / \Pi^{i c c *}=\left(3\left(4 \beta-k^{2}\right)^{2} \quad / 4\left(2 \beta-k^{2}\right)\left(6 \beta-k^{2}\right)\right)>1$, so $\Pi^{r c c *}>\Pi^{i c c *}$. In the same way, due to $c s^{r c c *}=\beta\left(a-\beta c_{m}-\right.$ $\left.\beta c_{s}\right)^{2} / 8\left(2 \beta-k^{2}\right)^{2}$ and $c s^{i c c *}=\beta\left(a-\beta c_{m}-\beta c_{s}\right)^{2} / 2\left(4 \beta-k^{2}\right)^{2}$, we can get $c s^{r c c *}>c s^{i c c *}$.

At the same time, combining the research conclusions of Proposition 1, we can get as follows: compared with the two power structures of manufacturer-led and LSI-led, whether it is from the perspective of maximizing the total profit of the supply chain and maximizing the consumer surplus, or from the perspective of different decision-making modes, the entire supply chain dominated by retailers is the optimal power structure.

Therefore, in the supply chain with the participation of two-echelon logistics service providers, small- and mediumsized enterprises (such as manufacturers and logistics service providers) should join the supply chain dominated by retailers, so as to maximize their own benefits, the overall benefits of the supply chain, and consumer surplus.

Proposition 8. Under the PSC centralized/LSSC centralized decision-making mode, the total profit of the supply chain of the Nash game adopted by two parties is the largest, while the total profit of the supply chain of the Stackelberg game adopted by LSSC is the smallest.

Proof in the PSC centralized/LSSC centralized decisionmaking mode, the following three power structures are considered, namely, the PSC and LSSC adopt Nash game, PSC adopts Stackelberg game, or LSSC adopts Stackelberg game. Among them, if the two sides adopt the Nash game, indicated with superscript $n$, PSC adopts Stackelberg game, indicated with superscript $p$, and LSSC adopts Stackelberg game, indicated with superscript $l$.

If PSC and LSSC adopt Nash game, at this time, let $\partial \prod_{p} / \partial p=0, \partial \prod_{l} / \partial p_{i}=0$, and $\partial \prod_{l} / \partial e=0$, and the Hessian matrix satisfies the negative definite criterion when $\beta>k^{2}$, and $a-\beta c_{m}-\beta c_{s} \geq 0$. We can get as follows: $p^{n c c}=(\alpha+$ $\left.k e+\beta c_{m}+\beta p_{i}\right) / 2 \beta, \quad p_{i}^{n c c}=\left((\alpha-\beta p) /\left(\beta-k^{2}\right)\right)+c_{s}$, and $e^{n c c}=k(\alpha-\beta p) / \beta-k^{2}$.

The optimal solutions can be obtained by combining the above three equations as follows: $p^{n c c *}=\left(2 \alpha+(\beta-k)^{2}\right.$ $\left.\left(c_{m}+c_{s}\right)\right) / 3 \beta-k^{2}, p_{i}^{n c c *}=\left(\left(\alpha-\beta c_{m}-\beta c_{s}\right) /\left(3 \beta-k^{2}\right)\right)+c_{s}$, $e^{n c c *}=k\left(\alpha-\beta c_{m}-\beta c_{s}\right) /\left(3 \beta-k^{2}\right)$, and $d^{n c c *}=\beta\left(\alpha-\beta c_{m}-\right.$ $\left.\beta c_{s}\right) /\left(3 \beta-k^{2}\right)$; substituting the above optimal solutions into two profit functions: the profit function of PSC and LSSC and the total profit function of the supply chain system, we can get $\prod^{n c c *}=\left(\left(4 \beta-k^{2}\right)\left(\alpha-\beta c_{m}-\beta c_{s}\right)^{2}\right) / 2\left(3 \beta-k^{2}\right)^{2}$, $\prod_{p}^{n c c *}=\beta\left(\alpha-\beta c_{m}-\beta c_{s}\right)^{2} /\left(3 \beta-k^{2}\right)^{2}$, and $\prod_{l}^{n c c *}=((2 \beta-$ $\left.\left.k^{2}\right)\left(\alpha-\beta c_{m}-\beta c_{s}\right)^{2}\right) /\left(2\left(3 \beta-k^{2}\right)^{2}\right)$; among them $\beta>k^{2}$ and $a-\beta c_{m}-\beta c_{s} \geq 0$.

If PSC adopts the Stackelberg game, the total profit of the supply chain is $\Pi^{p c c *}=3\left(a-\beta c_{m}-\beta c_{s}\right)^{2} /\left(8\left(2 \beta-k^{2}\right)\right)$.

If LSSC adopts Stackelberg game, the optimal solutions at this time are as follows: 


$$
\begin{aligned}
e^{l c c *} & =\frac{k\left(a-\beta c_{m}-\beta c_{s}\right)}{4 \beta-k^{2}}, \\
p^{l c c *} & =\frac{3\left(a-\beta c_{m}-\beta c_{s}\right)}{4 \beta-k^{2}}+c_{m}+c_{s}, \\
p_{i}^{l c c *} & =\frac{2\left(a-\beta c_{m}-\beta c_{s}\right)}{4 \beta-k^{2}}+c_{s}, \\
d^{l c c *} & =\frac{\beta\left(a-\beta c_{m}-\beta c_{s}\right)}{4 \beta-k^{2}}, \\
\Pi_{p}^{l c c *} & =\frac{\beta\left(a-\beta c_{m}-\beta c_{s}\right)^{2}}{\left(4 \beta-k^{2}\right)^{2}}, \\
\Pi_{l}^{l c c *} & =\frac{\left(a-\beta c_{m}-\beta c_{s}\right)^{2}}{2\left(4 \beta-k^{2}\right)^{2}}, \\
\prod^{l c c *} & =\frac{\beta\left(a-\beta c_{m}-\beta c_{s}\right)^{2}}{2\left(4 \beta-k^{2}\right)^{2}} . \\
2\left(4 \beta-k^{2}\right)^{2} & =\frac{\left(a-\beta c_{m}-\beta c_{s}\right)^{2}\left(6 \beta-k^{2}\right)}{2(a)},
\end{aligned}
$$

Due to $\prod^{n c c *} / \prod^{p c c *}=\left(4\left(4 \beta-k^{2}\right)\left(2 \beta-k^{2}\right)\right) /(3(3 \beta-$ $\left.\left.k^{2}\right)^{2}\right)$, the difference between its numerator and denominator is $5 \beta^{2}+k^{4}-6 \beta k^{2}$, and due to $\beta>k^{2}$, since $5 \beta^{2}+k^{4}-$ $6 \beta k^{2}>0$, so $\prod^{n c c *}>\prod^{p c c *}$.

In the same way, we can get $\prod^{p c c *}>\prod^{l c c *}$. So, $\prod^{n c c *}>\prod^{p c c *}>\prod^{l c c *}$. That is, the total profit of the supply chain is the largest under the Nash game, while the total profit of the supply chain is the smallest when the LSSC adopts the Stackelberg game.

Therefore, in PSC centralized/LSSC centralized decisionmaking mode, LSSC should gradually improve its leading ability in the whole supply chain system by integrating logistics resources and building logistics information service platform from the perspective of maximizing the total profit of the whole supply chain system.

Proposition 9. Under the PSC centralized/LSSC centralized decision-making mode, if the PSC has the dominant power, its profit level is the largest; if the leadership of PSC is equal to the leadership of LSSC, its profit level is second; if the LSSC has the dominant power, its profit is the minimum level. Similarly, there are consistent research conclusions for LSSC.

Proof:. according to the above calculation results: $\Pi_{p}^{p c c *}$ / $\Pi_{p}^{n c c *}=\left(\left(3 \beta-k^{2}\right)^{2} / 4 \beta\left(2 \beta-k^{2}\right)\right)>1, \Pi_{p}^{l c c *} / \Pi_{p}^{n c c *}=((3 \beta-$ $\left.\left.k^{2}\right)^{2} /\left(4 \beta-k^{2}\right)^{2}\right)<1$, therefore $\Pi_{p}^{p c c *}>\Pi_{p}^{n c c *}>\Pi_{p}^{l c c *}$. In the same way, we can get that $\Pi_{l}^{p c c *}<\Pi_{l}^{n c c *}<\Pi_{l}^{l c c *}$. That is to say, the dominant power of both PSC and LSSC will directly affect their respective profit levels, and the dominant party is easier to obtain greater profits. Therefore, both PSC and
LSSC have the enthusiasm to dominate the supply chain.

Proposition 10. Under the PSC centralized/LSSC centralized decision-making mode, the equilibrium strategy of the game between the two parties is to adopt the Nash game, and at this time, the logistics service level and consumer surplus are the largest, and the product retail price is the smallest while the logistics service level and consumer surplus under the Stackelberg game adopted by LSSC are the smallest and the retail price of the product is the largest.

Proof Table 5 shows the game structure of PSC centralized/ LSSC centralized decision-making mode under different dominant powers. The first item under each strategy in the table is the profit of PSC, and the second item is the profit of LSSC.

According to the research conclusions of Proposition 9, combined with the game structure of Table 5, we can get as follows: when PSC dominates the supply chain, the profit of LSSC when it chooses to be the leader is greater than the profit when it chooses to be the follower; at this time, the LSSC will choose to dominate. Similarly, when the LSSC chooses to dominate the supply chain, the profit of PSC when it chooses to dominate is greater than the profit when it chooses to follow. At this time, the PSC will choose to dominate; therefore, the equilibrium decision of the two sides of the game is as follows: the two sides adopt the Nash game.

According to Proposition 8, the retail price of the product under the Nash game is $p^{n c c *}=(2 \alpha+\quad(\beta-$ $\left.\left.k^{2}\right)\left(c_{m}+c_{s}\right)\right) /\left(3 \beta-k^{2}\right)$, the retail price of products under the Stackelberg game adopted by PSC is $p^{p c c *}=((3 \alpha \beta-$ $\left.\left.a k^{2}+\beta\left(\beta-k^{2}\right)\left(c_{m}+c_{s}\right)\right) / 2 \beta\left(2 \beta-k^{2}\right)\right)$, and the retail price of products under the Stackelberg game adopted by LSSC is $p^{l c c *}=\left(3 \alpha+\left(\beta-k^{2}\right)\left(c_{m}+c_{s}\right)\right) /\left(4 \beta-k^{2}\right)$, due to $p^{l c c *}-$ $p^{n c c *}=\left(\left(\left(\beta-k^{2}\right)\left(a-\beta c_{m}-\beta c_{s}\right)\right) /\left(\left(4 \beta-k^{2}\right)\left(3 \beta-k^{2}\right)\right)\right)>0$, $p^{p c c *}-p^{n c c *}=\left(\left(\begin{array}{ll}\left(\beta-k^{2}\right)^{2} & \left.\left(a-\beta c_{m}-\beta c_{s}\right)\right)\end{array} /(2 \beta(2 \beta-\right.\right.$ $\left.\left.\left.k^{2}\right)\left(3 \beta-k^{2}\right)\right)\right)>0$, and $p^{p c c *}<p^{l c c *}$, so $p^{n c c *}<p^{p c c *}<p^{l c c *}$. That is, the retail price of products under the Nash game is the smallest, while the retail price of products under the Stackelberg game led by LSSC is the largest.

In the same way, $e^{n c c *}=\left(k\left(\alpha-\beta c_{m}-\beta c_{s}\right) / 3 \beta-k^{2}\right)$, $e^{p c c *}=\left(k\left(\alpha-\beta c_{m}-\beta c_{s}\right) / 2\left(2 \beta-k^{2}\right)\right)$, and $e^{l c c *}=(k(\alpha-$ $\left.\left.\beta c_{m}-\beta c_{s}\right) / 4 \beta-k^{2}\right)$. Therefore, it can be proved that $e^{n c c *}>e^{p c c *}>e^{l c c *}$. That is to say, the logistics service level under the Nash game adopted by two parties is the largest, while the logistics service level under the Stackelberg game led by LSSC is the smallest. According to the above calculation formula of consumer surplus, it can be obtained that the consumer surplus under the Nash game adopted by two parties is the largest, while the consumer surplus under the Stackelberg game led by LSSC is the smallest, which is similar to the research conclusion of Gao [42]; that is, the market structure without leadership is better for the entire supply chain and consumers.

Combining the research conclusions of Propositions 8-10, we can get that PSC centralized/LSSC centralized 


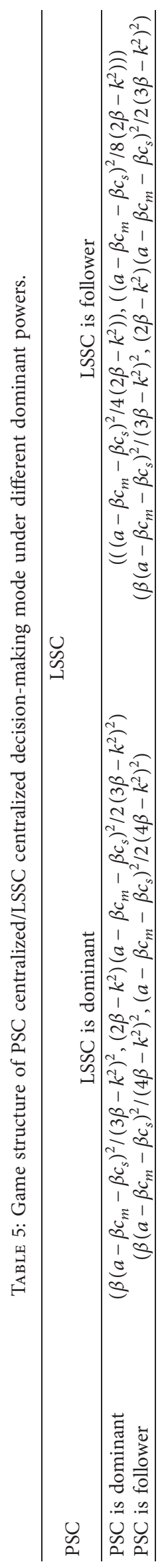


decision is a dominant strategy. At this time, the equilibrium strategy of both parties is to adopt Nash game; that is, PSC and LSSC jointly dominate the operation of the supply chain. At this time, the total profit of the supply chain is the largest, and the consumer surplus is the largest. If the status of PSC and LSSC is not equal, compared with LSSC-led Stackelberg game, PSC-led Stackelberg game can achieve greater supply chain profits and consumer surplus. At the same time, the dominant power of PSC and LSSC has a positive impact on their respective profit levels.

Therefore, the managerial implication is that LSSC should gradually improve its leading ability in the whole supply chain system to achieve a basic balance with PSC in PSC centralized/LSSC centralized decision-making mode.

\section{Numerical Analysis}

Referring to the research designs of most scholars, such as Zhang and Xing [43] and Sudipta et al. [44], this part will analyze and verify the main research conclusions of this paper more intuitively by means of numerical simulation. Under the premise of satisfying the basic assumptions of the model, the initial assignment of related parameters is as follows: $a=100, \beta=2, k=1, c_{m}=4$, and $c_{s}=3$.

\subsection{Comparative Analysis of Optimal Decisions with Different} Power Structures in Decentralized Decision-Making Mode Figure 3 simulates the impact of the logistics service level sensitivity coefficient $k$ on the total profit of the supply chain and consumer surplus under different power structures in the decentralized decision-making mode. The data in the figure shows that the total profit and consumer surplus of the supply chain led by the retailer are far greater than those led by the manufacturer and LSI, while the total profit and consumer surplus of the supply chain led by the LSI are the lowest, which is less different from the situation led by the manufacturer.

At the same time, with the increase of the sensitivity coefficient $k$ of logistics service level, the total profit gap of the supply chain and the gap of consumer surplus under different power structures have gradually widened, which further highlights the advantages of retailer as the leader of the supply chain. That is to say, if the retailer is facing consumers who are more sensitive to the logistics service level, it is more convenient for the retailer to dominate the whole supply chain to maximize the profit and consumer surplus. If the retailer is dealing with consumers who are less sensitive to the level of logistics services, at this time, the situation of manufacturer-led and LSI-led is almost the same.

Figure 4 simulates the impact of sensitivity coefficient $\beta$ of product retail price on the total profit of the supply chain and consumer surplus under different power structures in the decentralized decision-making mode. The data in the figure show that as the product retail price sensitivity coefficient $\beta$ decreases, under the different power structures, the supply chain total profit gap and consumer surplus gap have gradually widened, which further highlights the advantage of the retailer as the leader of supply chain. That is to say, if the retailer is facing consumers who are less sensitive to the retail price of the product, it is easier to maximize the profit of the entire supply chain and consumer surplus if the retailer is the leader.

In summary, in the decentralized decision-making mode, the retailer should dominate the entire supply chain, so that greater profits and consumer surplus can be achieved. At the same time, when the retailer is facing consumers who are less sensitive to product retail price and more sensitive to logistics service level, the advantage of supply chain led by the retailer is more significant.

Figure 5 simulates the impact of sensitivity coefficient $k$ of the logistics service level on the logistics service level and product retail price under different power structures in the decentralized decision-making mode. The data in the figure show that as the logistics service level sensitivity coefficient increases, the logistics service level and product retail price of the supply chain under different power structures have gradually increased, and the retailer-led supply chain has the largest logistics service level and the smallest product retail price. While the logistics service level led by LSI is the smallest and the product retail price is the largest.

6.2. Comparative Analysis of Optimal Decisions of Different Power Structures in PSC Centralized/LSSC Centralized Decision-Making Mode. Figures 6 and 7, respectively, simulate the impact of sensitivity coefficient $k$ of the logistics service level on the total supply chain profit, consumer surplus, logistics service level, and product retail price under different power structures in the PSC centralized/LSSC centralized decision-making mode.

The data in the figure show that the total supply chain profit, logistics service level, and consumer surplus under the Nash game are the largest, and the retail price of the product is the smallest, while the results under the LSSC-led are the opposite. Under different power structures, the total profit of the supply chain, consumer surplus, logistics service level, and product retail price all increase with the increase of $k$.

At the same time, as the sensitivity coefficient $k$ of logistics service level increases, the gap of supply chain total profits and consumer surplus under PSC-led and Nash game is getting smaller, while the gap of supply chain total profits and consumer surplus under PSC-led and LSSC-led situations is growing. That is to say, when PSC is facing consumers with a high level of logistics service sensitivity, the difference between the two parties adopting the Nash game or the PSC-led Stackelberg game is small. While when PSC is facing consumers with low logistics service level sensitivity, the advantage of Nash game adopted by PSC and LSSC is more obvious.

Figure 8 simulates the impact of sensitivity coefficient $\beta$ of the product retail price on the total profit of the supply chain and consumer surplus under different power structures in the PSC centralized/LSSC centralized decisionmaking mode. The data in the figure show that as the sensitivity coefficient of product retail price increases, the 


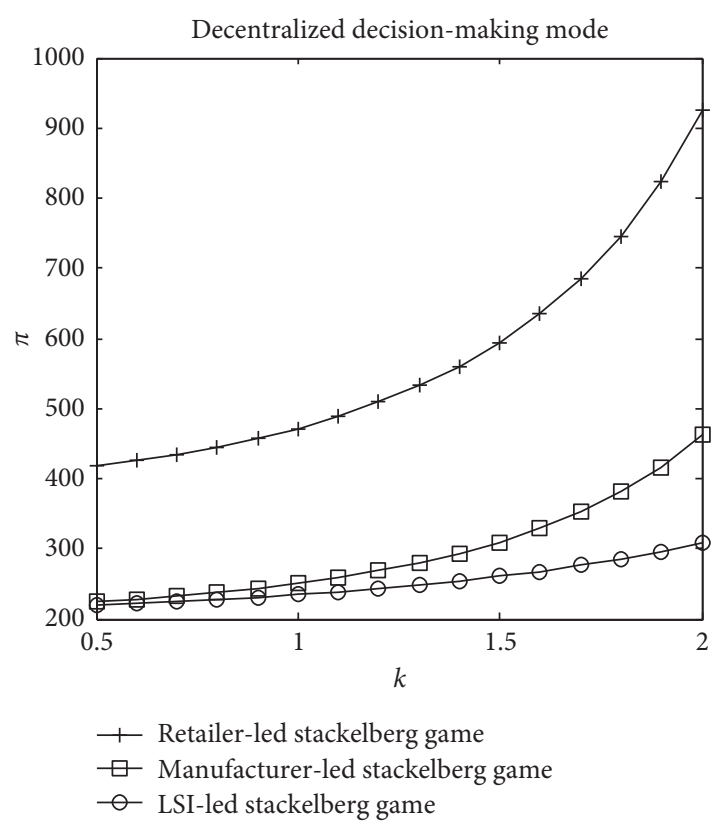

(a)

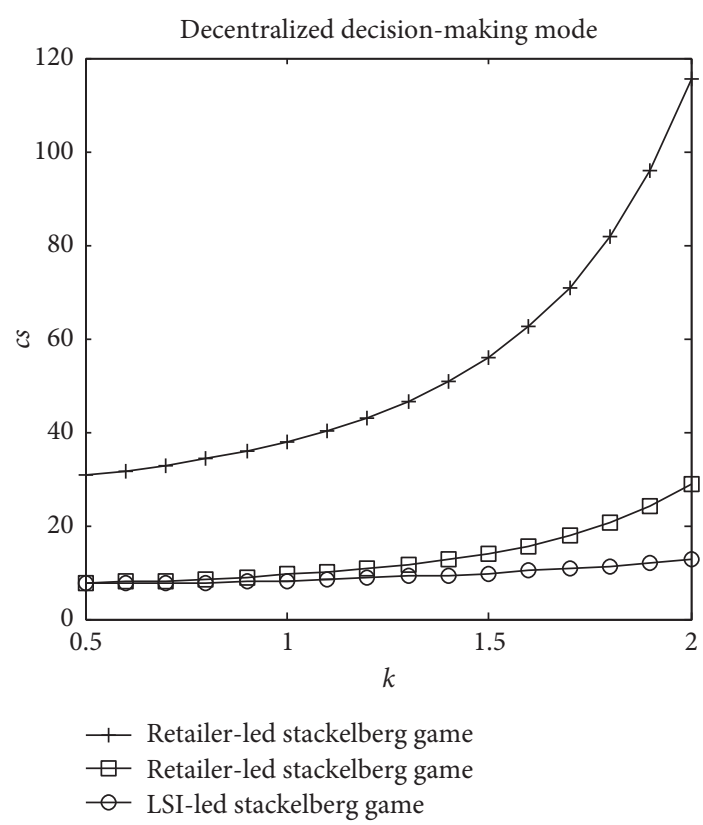

(b)

Figure 3: Trends of $\Pi^{d d *}$ and $c s^{d d *}$ with $k$ under different power structures.
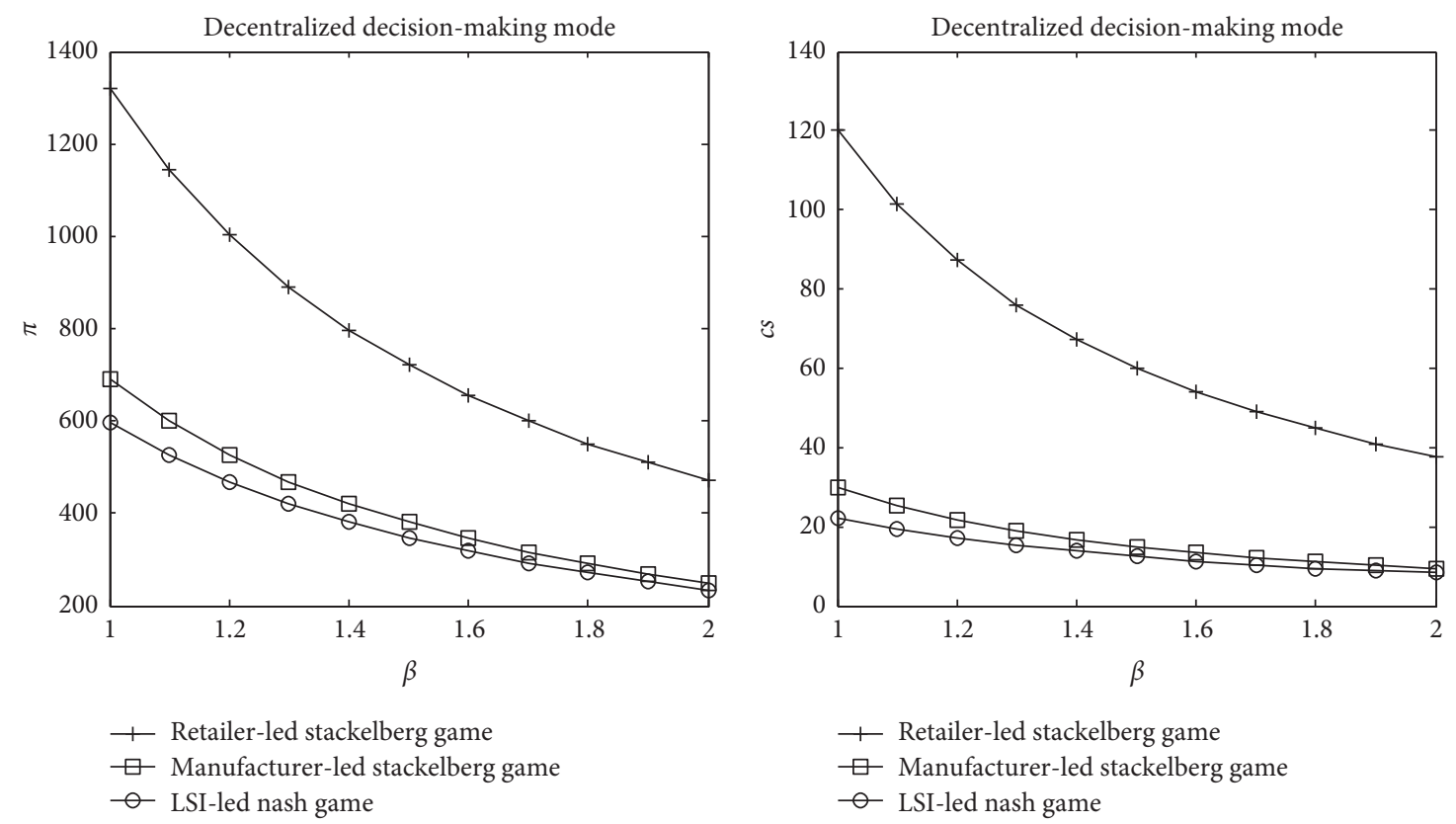

(a)

(b)

Figure 4: Trends of $\Pi^{d d *}$ and $c s^{d d *}$ with $\beta$ under different power structures. 


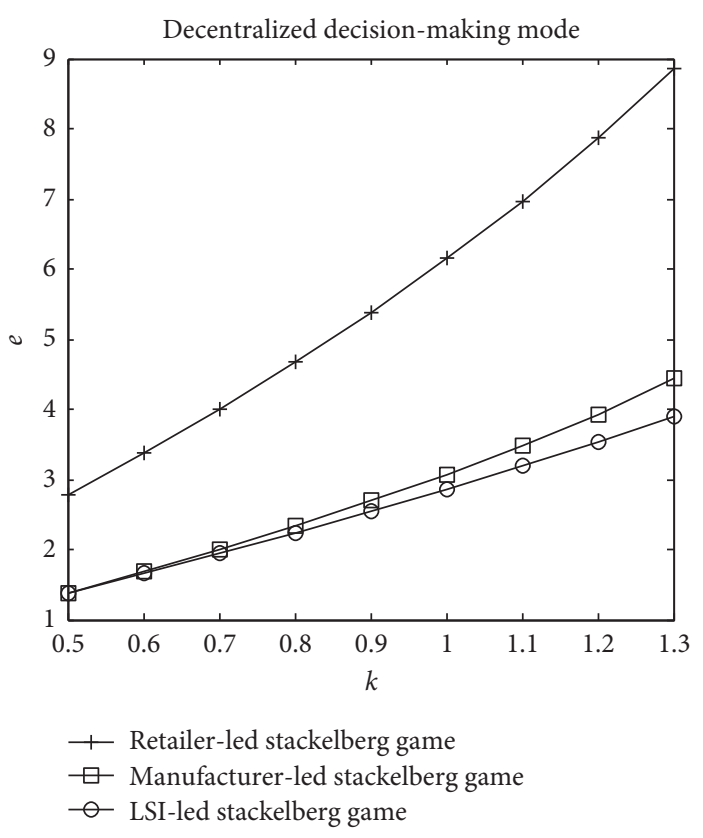

(a)

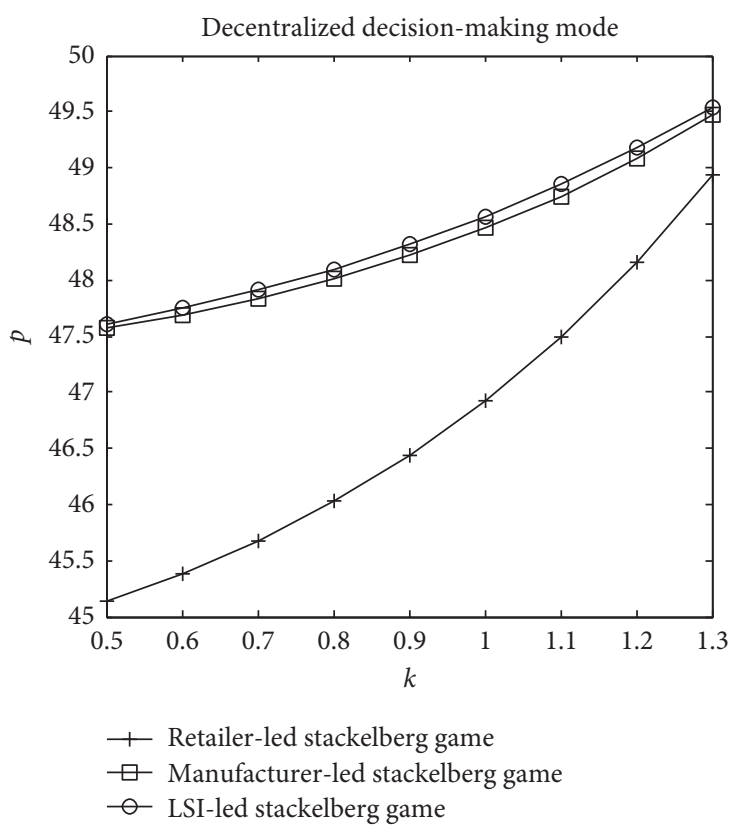

(b)

FIgURE 5: Trends of $e^{d d *}$ and $p^{d d *}$ with $k$ under different power structures.

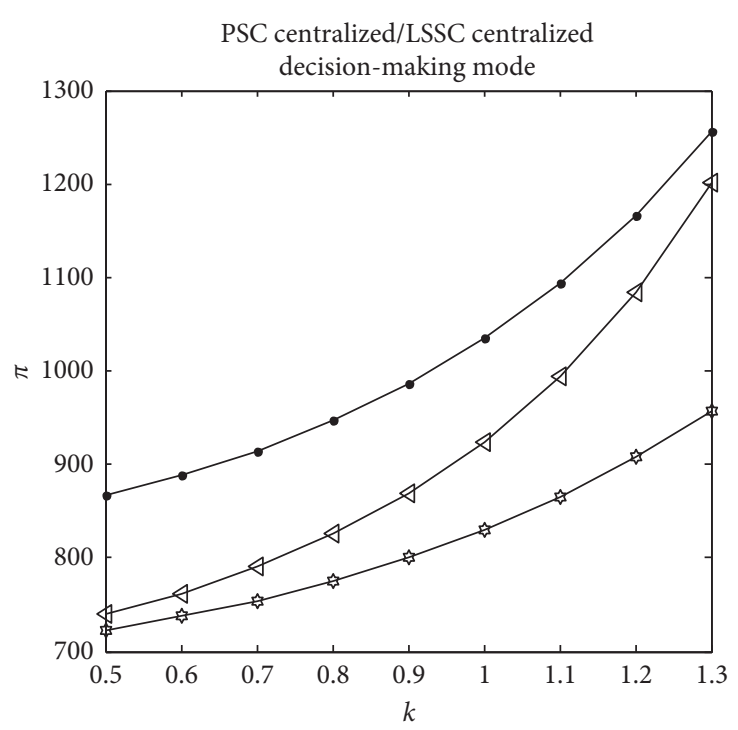

$\triangleleft$ PSC-led stackelberg game

$\nleftarrow$ LSSC-led stackelberg game

$\rightarrow$ Nash game

(a)

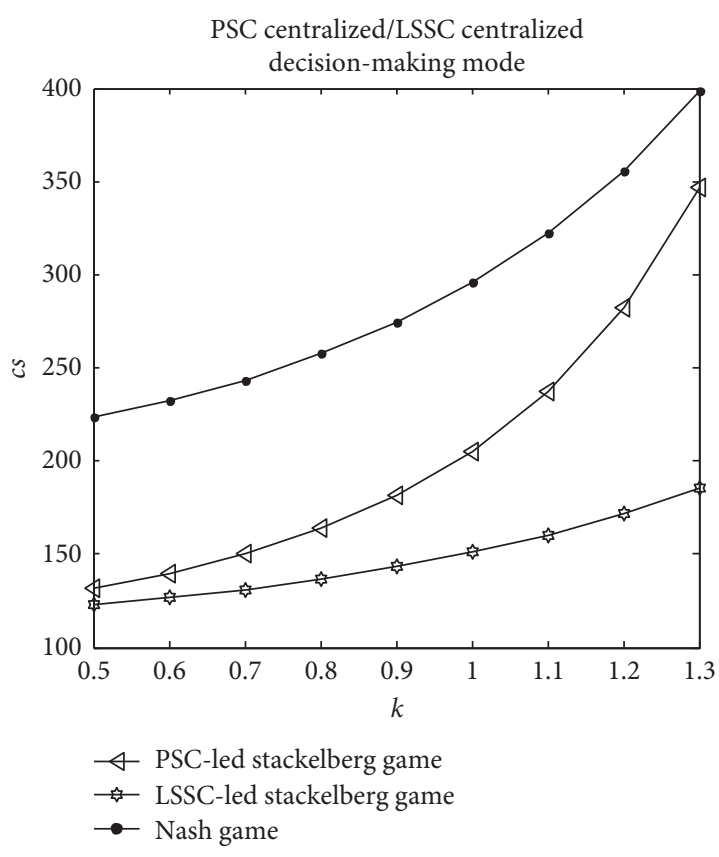

(b)

Figure 6: Trends of $\Pi^{c c *}$ and $c s^{c c *}$ with $k$ under different power structures. 


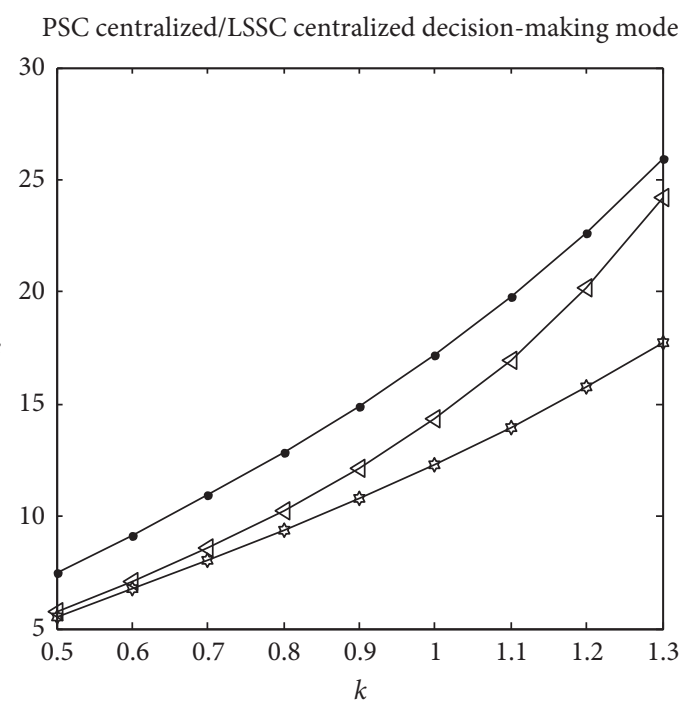

$\triangleleft$ PSC-led stackelberg game

* LSSC-led stackelberg game

$\rightarrow$ Nash game

(a)
PSC centralized/LSSC centralized decision-making mode

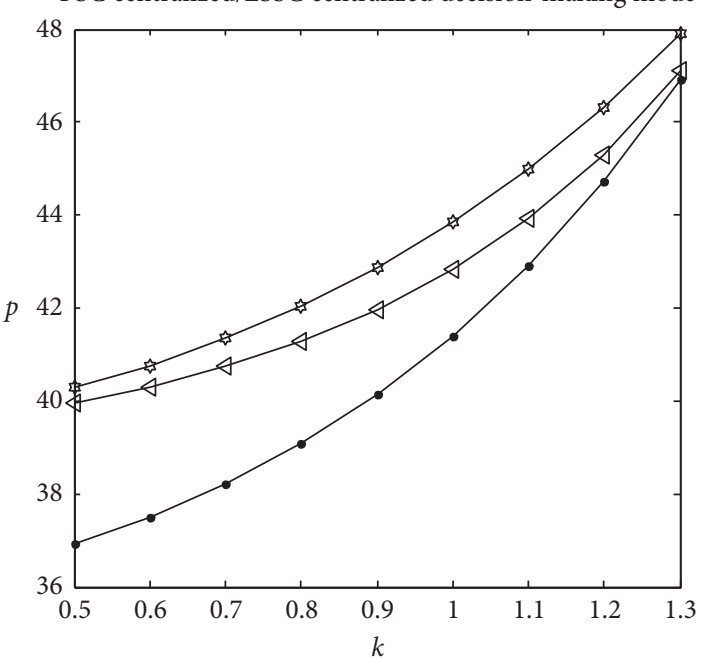

$\dashv$ PSC-led stackelberg game

LSSC-led stackelberg game

$\rightarrow$ Nash game

Figure 7: Trends of $e^{c c *}$ and $p^{c c *}$ with $k$ under different power structures.

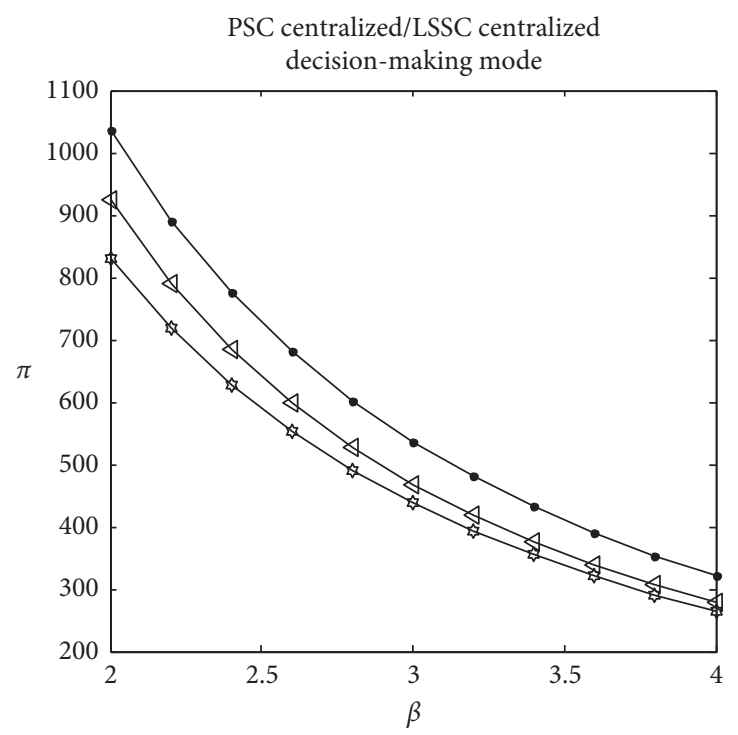

$\dashv$ PSC-led stackelberg game

* LSSC-led stackelberg game

$\rightarrow$ Nash game

(a)

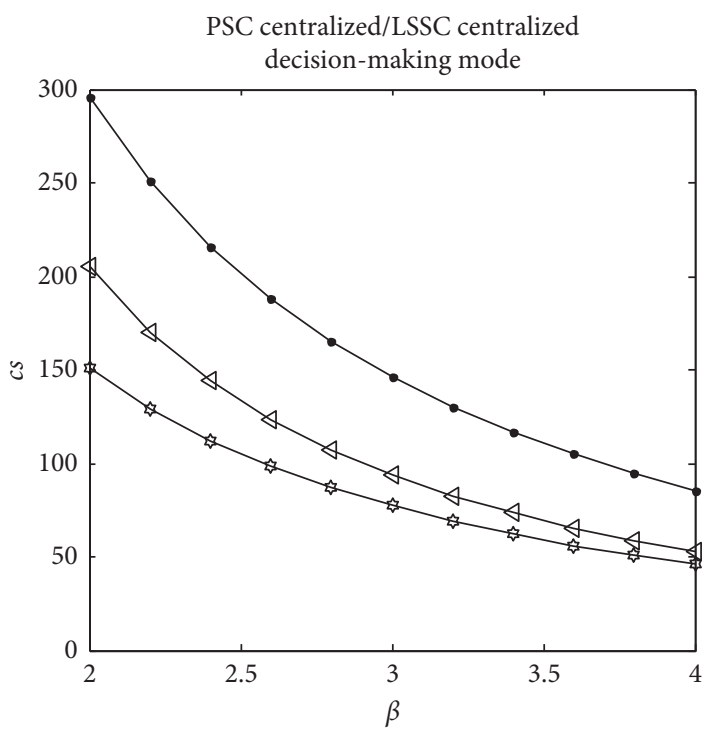

$\dashv$ PSC-led stackelberg game

LSSC-led stackelberg game

$\rightarrow$ Nash game

(b)

Figure 8: Trends of $\Pi^{c \mathcal{c} *}$ and $c s^{c c *}$ with $\beta$ under different power structures. 
gap in the total profit of the supply chain and the gap in consumer surplus under the three power structures of Nash game, PSC-led Stackelberg game, and LSSC-led Stackelberg game have gradually narrowed. That is to say, when PSC is facing consumers who are less sensitive to the retail price of the product, the advantages of the Nash game between the two parties are more significant.

In summary, PSC and LSSC should adopt the Nash game in the PSC centralized/LSSC centralized decision-making mode. When the supply chain faces consumers who are less sensitive to the logistics service level and the product retail price, the advantages of the Nash game adopted by two parties are more obvious. When PSC is facing consumers with a high level of logistics service sensitivity, the two parties can adopt the Nash game or the PSC-led Stackelberg game. At this time, the gap between the two parties is small. When PSC is facing consumers who are more sensitive to product retail price and when the two parties adopt the PSCled or LSSC-led Stackelberg game, the gap of the total supply chain profits and consumer surplus is small.

\section{Main Research Conclusions and Future Research Directions}

This paper studies the optimal decisions of the four-level supply chain with the participation of two-echelon logistics service providers under different power structures and analyzes the influence of the power structures on the optimal decisions of the supply chain systematically. It explores the optimal cooperative decision-making mode for improving the operating efficiency of supply chain systems under different power structures. Research shows that in the decentralized decision-making mode, since the status of each decision maker cannot be equal, the retailer-led supply chain has the largest total profit and consumer surplus, and the LSI-led supply chain has the smallest total profit and consumer surplus. At the same time, when retailer is facing the consumers who are less sensitive to product retail price and more sensitive to logistics service level, the advantage of the decentralized supply chain led by retailer is even more significant.

Under different power structures, the profit of PSC when it chooses centralized decision-making mode is greater than that of PSC when it chooses decentralized decision-making mode. Therefore, in the long run, the manufacturer and retailer will gradually form strategic alliance for centralized decision-making; when PSC chooses centralized decisionmaking mode, the profit of LSSC when it chooses centralized decision-making mode is the largest under different power structures. At this moment, LSI will gradually form a longterm strategic partnership with FLSP. Therefore, under the drive of profit maximization, the PSC centralized/LSSC centralized decision is the dominant strategy. At this time, the total profit of the supply chain system increases, and the profits of PSC and LSSC will increase.

When the entire supply chain implements the PSC centralized/LSSC centralized decision-making mode, the equilibrium strategy is that PSC and LSSC adopt the Nash game; at this moment, the total profit of the supply chain system and the total social welfare are the largest, while the total profit of the supply chain and consumer surplus under the leadership of LSSC are the smallest. When PSC is facing consumers who are more sensitive to logistics service level, both parties can adopt the Nash game or the PSC-led Stackelberg game. At this time, the gap of the total supply chain profit and consumer surplus of the two parties is relatively small. When PSC is facing consumers who are less sensitive to logistics service level and less sensitive to product retail price, PSC and LSSC have a more significant advantage in adopting the Nash game.

The limitations of this study lie in the following aspects. First, this paper only studies the optimal decisions of a single-channel supply chain involving two-echelon logistics service providers. In the future, we can further study the optimal decisions of a dual-channel supply chain involving two-echelon logistics service providers. Besides, we can have an overall consideration that customer needs are also simultaneously affected by product retail price, logistics service level, and offline comprehensive experience service levels, and we will further analyze the optimal decisions under different power structures based on online and offline competition around service levels, online and offline freeriding, etc. Second, this paper only studies the optimal decisions when the market demand is determined, and we can further study the optimal power structure selection and the optimal decision-making mode when the market demand is uncertain in the future, which may draw more valuable conclusions and managerial implications.

\section{Data Availability}

The data used to support the findings of this study are available from the corresponding author upon request.

\section{Conflicts of Interest}

The authors declare no conflicts of interest.

\section{Acknowledgments}

This work was supported by the General Project of $\mathrm{Hu}-$ manities and Social Sciences of China Education Ministry (grant no. 20YJA630090), Social Science Fund Project in Inner Mongolia (Research on the Improvement of Agricultural Products Supply Chain in Inner Mongolia), and Project of Inner Mongolia Rural Pastoral Development Research Institute.

\section{References}

[1] D. Waters, Global Logistics and Distribution Planning: Strategies for Management, pp. 1-32, Kogan Page, London, UK, 2003.

[2] J. J. Zhang and Q. L. Zhao, "Research on the evolution mechanism of the interactive development between product supply chain and logistics service supply chain based on "internet +" - - from the angel of "disintermediation" to "decentralized"," Journal of Business Economics, vol. 05, pp. 5-15, 2017. 
[3] C. H. Ma, "Study on collaboration of logistics service supply chain based on competence cooperation," China's Circulation Economy, vol. 2, pp. 24-27, 2009.

[4] J. Heydari, "Coordinating supplier's reorder point: a coordination mechanism for supply chains with long supplier lead time," Computers \& Operations Research, vol. 48, pp. 89-101, 2014.

[5] H. Song, Supply Chain Finance, China Renmin University Press, Beijing, China, 2nd edition, 2016.

[6] A. L. EI-Ansary and L. W. Stern, "Power measurement in the distribution channel," Journal of Marketing Research, vol. 9, no. 1, pp. 47-52, 1972.

[7] Y. Feng and Y. Z. Zhang, "Decision making and efficiency evaluation in a supply China with TPL's value-added services under different power structures," Chinese Journal of Management Science, vol. 26, no. 10, pp. 164-175, 2018.

[8] Y. Xia and S. M. Gilbert, "Strategic interactions between channel structure and demand enhancing services," European Journal of Operational Research, vol. 181, no. 1, pp. 252-265, 2007.

[9] J. Cui, "The influences of different dominent structure of supply chain on the market integration of differentiated competitive manufacturers," Commercial Research, vol. 12, pp. 57-65, 2019.

[10] C. Feng, L. Y. Li, and X. S. Fang, "Impacts of power structure on supply chain with random yield," Computer Integrated Manufacturing Systems, vol. 24, no. 06, pp. 1542-1553, 2018.

[11] M. M. Nikunja, P. Shibaji, and S. S. Shib, "Three-echelon supply chain coordination considering duopolistic retailers with perfect quality products," International Journal of Production Economics, vol. 182, pp. 564-578, 2016.

[12] Y. Yu and T. Xiao, "Pricing and cold-chain service level decisions in a fresh agri-products supply chain with logistics outsourcing," Computers \& Industrial Engineering, vol. 111, no. 7, pp. 56-66, 2017.

[13] X. Li, Y. J. Li, X. Q. Cai et al., "Service channel choice for supply chain: who is better off by undertaking the service?" Production and Operations Management, vol. 25, pp. 516-534, 2016.

[14] B. C. Giri, A. Chakraborty, and T. Maiti, "Pricing and return product collection decisions in a closed-loop supply chain with dual-channel in both forward and reverse logistics," Journal of Manufacturing Systems, vol. 42, pp. 104-123, 2017.

[15] J. Zhang, S. Zhao, T. C. E. Cheng, and G. Hua, "Optimisation of online retailer pricing and carrier capacity expansion during low-price promotions with coordination of a decentralised supply chain," International Journal of Production Research, vol. 57, no. 9, pp. 2809-2827, 2019.

[16] X. S. Fan, Z. L. Yang, and J. P. Wang, "Closed-loop supply chain coordination model under uncertain demand and collection," Journal of Hefei University of Technology(Natural Science), vol. 08, pp. 108-114, 2014.

[17] S. Subrata, S. P. Sarmah, and I. Moon, "Dual channel closed-loop supply chain coordination with a rewarddriven remanufacturing policy," International Journal of Production Research, vol. 54, no. 5, pp. 1503-1517, 2016.

[18] Y. Yu, "Research on coordination contract of dual-channel supply chain under the influence of logistics service level on demand," Southeast Academic Research, vol. 3, pp. 133-139, 2015.

[19] S. Subrata, "Channel characteristics and coordination in three-echelon dual-channel supply chain," International Journal of Systems Science, vol. 47, no. 3, pp. 740-754, 2016.
[20] H. D. Gan, The Study on Coordination and Profit Allocation of Medical Supply Chain with the Third Party Logistics Involved, ZheJiang University, Hnagzhou, China, 2012.

[21] S. S. Shib, "A structural mathematical model on two echelon supply chain system," Annals of Operations Research, 2021.

[22] E. N. Izabela, S. Majumder, and S. Saha, "Exploring the intervention of intermediary in a green supply chain," Journal of Cleaner Production, vol. 233, pp. 1525-1544, 2019.

[23] S. Subrata, S. Majumder, and I. E. Nielsen, "Is it a strategic move to subsidized consumers instead of the manufacturer?" IEEE Access, vol. 7, pp. 169807-169824, 2019.

[24] S. Khalifehzadeh, M. Seifbarghy, and B. Naderi, "A four-echelon supply chain network design with shortage: mathematical modeling and solution methods," Journal of Manufacturing Systems, vol. 35, no. 4, pp. 164-175, 2015.

[25] G. Abolfazl and H. R. Seyed, "Four-echelon integrated supply chain model with stochastic constraints under shortage condition: sequential quadratic programming," Industrial Engineering \& Management Systems, vol. 16, no. 3, pp. 316329, 2017.

[26] R. Hamed, S. Fatemeh, and R. Masoud, "Integrated production-distribution planning problem in a competitionbased four-echelon supply chain," Computers \& Industrial Engineering, vol. 119, no. 3, pp. 85-99, 2018.

[27] V. Olivares, A. Daniel, B. Olivares et al., "Combined use of mathematical optimization and design of experiments for the maximization of profit in a four-echelon supply chain," Complexity, vol. 19, no. 4, pp. 35-58, 2018.

[28] P. Hasanov, M. Y. Jaber, and N. Tahirov, "Four-level closed loop supply chain with remanufacturing," Applied Mathematical Modelling, vol. 66, pp. 141-155, 2019.

[29] Q. S. Liu, X. Y. Hu, and Y. Z. Hou, "Four-level supply chain coordination under emergency with revenue sharing contract," Science and Technology Management Research, vol. 33, no. 12, pp. 228-233, 2013.

[30] Y. J. Han, B. L. Shi, and J. Wang, "Research on product quality control of four levels supply chain under incentive strategy and revenue sharing contract," Industrial Engineering and Management, vol. 24, no. 01, pp. 37-44+95, 2019.

[31] A. Arnab, B. Arnab, and A. Balram, "Coordination mechanism, risk sharing, and risk aversion in a five-level textile supply chain under demand and supply uncertainty," European Journal of Operational Research, vol. 282, pp. 93-107, 2020.

[32] J. Heydari, P. Zaabi-Ahmadi, and T.-M. Choi, "Coordinating supply chains with stochastic demand by crashing lead times," Computers \& Operations Research, vol. 100, pp. 394-403, 2018.

[33] S. S. Sana, "Price competition between green and non green products under corporate social responsible firm," Journal of Retailing and Consumer Services, vol. 55, Article ID 102118, 2020.

[34] J. J. Zhang and Q. L. Zhao, “The optimal decision and interest distribution of supply chain involving two-echelon logistics service providers-based on multiple decision-making modes," Journal of Business Economics, vol. 06, pp. 15-29, 2019.

[35] H. Jafar and A.-N. Javad, "A revised sales rebate contract with effort-dependent demand: a channel coordination approach," International Transactions in Operational Research, vol. 28, no. 1, pp. 438-469, 2021.

[36] A. T. Andy and A. Narendra, "Channel dynamics under price and service competition," Manufacturing \& Service Operations Management, vol. 2, no. 4, pp. 372-391, 2000. 
[37] C.-C. Hsieh and Y.-T. Liu, "Quality investment and inspection policy in a supplier-manufacturer supply chain," European Journal of Operational Research, vol. 202, no. 3, pp. 717-729, 2010.

[38] H. Jafar and R. Pooya, "Integration of environmental and social responsibilities in managing supply chains: a mathematical modeling approach," Computers \& Industrial Engineering, vol. 145, Article ID 106495, 2020.

[39] R. Saeed, H. Abdorrahman, and M. H. Seyyed, "Proposing channel coordination and horizontal cooperation in two competitive three-echelon reverse supply chains," International Transactions in Operational Research, vol. 8, pp. 1-31, 2019.

[40] B. C. Giri and B. R. Sarker, "Improving performance by coordinating a supply chain with third party logistics outsourcing under production disruption," Computers \& Industrial Engineering, vol. 103, pp. 168-177, 2017.

[41] S. Neha, S. R. Singh, and S. S. Sana, "A green supply chain model of vendor and buyer for remanufacturing," RAIROOperations Research, vol. 51, no. 4, pp. 1133-1150, 2017.

[42] J. Gao, "Pricing and service decision-making of CLSC under different channel power structures," Statistics \& Decision, vol. 34, no. 18, pp. 48-53, 2018.

[43] J. J. Zhang and D. N. Xing, "Decision optimization and interest coordination of dual-channel supply chain embedded by two-echelon logistics service providers under the dominance of retailer," Mathematical Problems in Engineering, vol. 2020, Article ID 3020315, , 2020.

[44] S. Sudipta, N. M. Modak, and S. S. Sana, "An entropic order quantity inventory model for quality assessment considering price sensitive demand," Opsearch, vol. 57, no. 1, pp. 88-103, 2020 . 